Portland State University

PDXScholar

Civil and Environmental Engineering Faculty

Publications and Presentations

Civil and Environmental Engineering

8-1-2007

\title{
Pricing in Dynamic Vehicle Routing Problems
}

Miguel Andres Figliozzi

Portland State University

Hani S. Mahmassani

Patrick Jaillet

Follow this and additional works at: https://pdxscholar.library.pdx.edu/cengin_fac

Part of the Civil and Environmental Engineering Commons

Let us know how access to this document benefits you.

\section{Citation Details}

Figliozzi, M., Mahmassani, H. S., \& Jaillet, P. (2007). Pricing in Dynamic Vehicle Routing Problems.

Transportation Science, 41(3), 302-318.

This Article is brought to you for free and open access. It has been accepted for inclusion in Civil and Environmental Engineering Faculty Publications and Presentations by an authorized administrator of PDXScholar.

Please contact us if we can make this document more accessible: pdxscholar@pdx.edu. 


\title{
Pricing in Dynamic Vehicle Routing Problems
}

\author{
Miguel Andres Figliozzi \\ Faculty of Economics and Business, Institute of Transport and Logistics Studies, University of Sydney, \\ Sydney, NSW 2006, Australia, miguel@itls.usyd.edu.au \\ Hani S. Mahmassani \\ Department of Civil and Environmental Engineering, Martin Hall, University of Maryland, College Park, \\ College Park, Maryland 20742, masmah@umd.edu \\ Patrick Jaillet \\ Department of Civil and Environmental Engineering, Massachusetts Institute of Technology, \\ Cambridge, Massachusetts 02139-4307, jaillet@mit.edu
}

\begin{abstract}
$\mathrm{T}_{\mathrm{d}}^{\mathrm{h}}$ he principal focus of this paper is to study carrier pricing decisions for a type of vehicle routing problems defined in a competitive and dynamic environment. This paper introduces the vehicle routing problem in a competitive environment (VRPCE) as an extension of the traveling-salesman problem with profits (TSPP) to a dynamic competitive auction environment. In the VRPCE, the carrier must estimate the incremental cost of servicing new service requests as they arrive dynamically. The paper presents a rigorous and precise treatment of the sequential pricing and costing problem that a carrier faces in such an environment. The sequential pricing problem presented here is an intrinsic feature of a sequential auction problem. In addition to introducing the formulation of this class of problems and discussing the main sources of difficulty in devising a solution, a simple example is constructed to show that carriers' prices under first-price auction payment rules do not necessarily reflect the cost of servicing transportation requests. An approximate solution approach with a finite rolling horizon is presented and illustrated through numerical experiments, in competition with a static approach with no look-ahead.

Key words: freight transportation; dynamic vehicle routing; carrier fleet management strategies; pricing; carrier profitability; bidding strategies; auctions; electronic commerce

History: Received: April 2006; revisions received: September 2006, February 2007; accepted: February 2007.
\end{abstract}

\section{Introduction}

The principal focus of this paper is carrier pricing decisions for a new type of vehicle routing problems defined in a competitive and dynamic environment. This class of problems is best introduced in the context of the evolution of the freight transportation industry (deregulation) in the '80s and the explosive growth of the information and communication industries in the '90s.

The transportation industry became highly competitive in the United States after the U.S. Congress passed motor carrier deregulation legislation in the late 1970s and early 1980s. As a result, competition in the trucking industry is fierce, aided by relatively low capital entry requirements (especially in the truckload (TL) sector), and reflected in the large number of trucking companies (Coyle, Bardi, and Novac 2000). Operating ratios as tight as 0.95 (allowing just five cents per dollar earned to cover fixed costs, interest cost, and return to owners/taxes) are considered standard for TL companies (TCA 2003).

Information and communication technologies (ICT) are reducing pre- and posttransaction costs such as search, communication, quote request/preparation, and monetary exchanges. Ubiquitous and reliable communication networks are allowing physical decentralization of decision-making processes while connecting market agents in real time. As transaction time, cost, and effort reductions take place, sourcing and procurement strategies adjust to the new market environment (Dai and Kauffman 2002). The side effect of cheaper and improved market information, as well as higher transparency, can lead to increased competition (Zhu 2004). Nandiraju and Regan (2005) present a review of transportation marketplaces and their characteristics.

In a competitive transportation market, carriers typically face two distinct, although interrelated, decision problems: (1) a cost minimization problem (operating the fleet in the most efficient manner) and (2) an incremental cost and price determination problem (needed for contract tendering). The first type of problem is best described in the operations research (OR) literature by the family of problems widely known as vehicle routing problems (VRP). The second type of problem, despite its significance in competitive 
markets, has not received as much attention in the OR and vehicle routing literature, but is gaining traction in the operations management literature under the growing subarea of revenue management.

To study carriers' pricing in a competitive transportation market, this paper introduces the vehicle routing problem in a competitive environment (VRPCE) as an extension of the traveling-salesman problem with profits (TSPP) to a dynamic competitive auction environment. In the VRPCE, the carrier must estimate the incremental cost of servicing new service requests as they arrive dynamically. The paper presents a rigorous and precise treatment of the sequential pricing and costing problem that a carrier faces in such an environment. The sequential pricing problem is an intrinsic feature of a sequential auction problem. In addition to introducing the formulation of this class of problems and discussing the main sources of difficulty in devising a solution, a simple example is constructed to show that carriers' prices under first-price auction payment rules do not necessarily reflect the cost of servicing transportation requests. An approximate solution approach with a finite look-ahead horizon is presented and illustrated through numerical experiments, in competition with a static approach with no look-ahead.

This paper is organized as follows. Section 1 presents a literature review of the relevant VRP literature. Section 2 describes the VRPCE and introduces the mathematical notation necessary to describe the problem. Mathematical properties of pricing inherent to the VRPCE are shown and discussed in §3. Section 4 illustrates the equations and calculation process for a VRPCE example. Section 5 considers pricing with alternative payment (reward) mechanisms. Section 6 discusses the computational complexity of the VRPCE, proposes a simplified heuristic procedure, and analyzes its properties via simulation results. Section 7 reviews key informational and behavioral assumptions of the VRPCE, and is followed by concluding comments in a final section.

\section{VRP Background Review}

This section places the VRPCE in the context of the main known classes of the VRP and does not provide a comprehensive review of the extensive literature related to the VRP.

First introduced by Dantzig and Ramser (1959) in what they called the truck-dispatching problem, the VRP was formulated as an offshoot of the travelingsalesman problem (TSP) to capture multiple vehicles (with and without capacity constraints) and routes. Among many other extensions, the time windows VRP is widely encountered (Solomon and Desrosiers 1988). The objective in that case is to build up routes that minimize total distance while satisfying all customers' time windows. Other extensions include heterogeneous fleet capacity, compatibility constraints between vehicles/cargo/customers, pickup and delivery problems, several depots, driver-related constraints (maximum number of driving hours or mandatory rests), and generalized cost functions (combination of distance, time driven, and vehicle type). A thorough and comprehensive review of deterministic and static problems can be found in Toth and Vigo (2002).

Problems where customers (demand) or travel (service) times are not deterministic give rise to stochastic versions of the VRP. Jaillet (1988) introduced the a priori solution approach to the probabilistic TSP with stochastic customer requests (when the truck leaves the depot, there is uncertainty regarding what set of customers have to be served), later generalized to the VRP with stochastic customers and demand (Gendreau, Laporte, and Seguin 1996; Bertsimas, Jaillet, and Odoni 1990; Jaillet and Odoni 1988). Stochastic travel times in vehicle routing problems were introduced in Stewart and Golden (1983) and analyzed further in Laporte, Louveaux, and Mercure (1992) under general stochastic programming formulations (e.g., using chance constraints). Laporte and Louveaux (1993) presented an L-shaped solution for the stochastic integer program with complete recourse and first-stage binary variables.

Powell, Jaillet, and Odoni (1995) present a discussion of dynamic network modeling problems that arise in logistics and distribution systems, including a priori optimization and online decision policies for dynamic vehicle routing problems where information about customers or the system is revealed over time. Powell developed early models for the dynamic VRP (Powell 1986, 1987). Recent contributions to this problem include: approaches to anticipate future events using multiple-scenario analysis (Bent and Van Hentenryck 2004), sampling future scenarios (Mitrovic-Minic, Krishnamurthi, and Laporte 2004; Hvattum, Lokketangen, and Laporte 2006), vehicle waiting strategies (Branke et al. 2005; Mitrovic-Minic and Laporte 2004), anticipation of customer requests using a Markov process approach (Thomas and White 2004), and using knowledge about future demand arrivals in a real-time setting (Hemert and La Poutre 2004; Ichoua, Gendreau, and Potvin 2006).

Dynamic fleet management problems where the decision variables are assignment of vehicles (resources) to shipments (tasks) have also been studied in the literature, e.g., Powell's (1996) model for the dynamic assignment problem. Recent work has focused on studying the properties of these assignment models as well reducing the required computational effort, e.g., 
through approximations to the concave dynamic program value function (Topaloglu and Powell 2003). The effectiveness and computational complexity of the approximations are problem dependent. For example, problems with homogeneous vehicle types and one-period shipment service times can be efficiently approximated with a piecewise-linear function that provides integer solutions (Godfrey and Powell 2002), whereas problems with heterogeneous vehicle types and multiperiod service times require more elaborate approaches (Topaloglu and Powell 2002).

A common objective found throughout the literature is to minimize transportation costs, generally in regard to empty distance, driving time, or a combination of distance and time. Although costing is part of any dynamic problem (costs are implicitly considered because current decisions affect the cost of serving future shipments), costing and pricing are usually not an explicit part of VRP (deterministic, stochastic, or dynamic) formulations.

Profits are explicitly considered in the "TravelingSalesman Problem with Profits" or TSPP, as stated by Feillet, Dejax, and Gendreau (2005) in a comprehensive survey. These TSPP problems can be divided into three categories according to Feillet, Dejax, and Gendreau (2005): (a) profit tour problems $(\mathrm{PTP}),(\mathrm{b})$ orienteering problems (OP), and (c) prizecollecting TSPs (PCTSP). These problems not only include a known profit for visiting a customer/city, but also relax the condition that every customer must be visited. In the PTP (Dell'Amico, Maffioli, and Värbrand 1995), the objective is to find a TSP tour that maximizes total collected profits minus travel costs. The OP (Golden, Levy, and Vohra 1987) is similar to the PTP, with a constraint on total travel or cost. Finally, the PCTSP (Balas 1989) is similar to the PTP, but with a constraint on the amount of profit that must be collected in a tour.

Another line of research that explicitly includes profits and routing problems is the work on sequential auctions for transportation, where contracts (shipments) dynamically arrive at a marketplace and carriers compete for them in a sequence of oneshipment auctions. These sequential auctions enable the sale of cargo capacity based mainly on price, yet still satisfy customer level of service demands. This work belongs to this line of research. Figliozzi, Mahmassani, and Jaillet (2003a) present a framework to study transportation marketplaces and to compare the competitiveness of different vehicle routing strategies. Using this framework, Figliozzi, Mahmassani, and Jaillet (2004) compare four different methods to estimate service costs, including a simple look-ahead heuristic that averages the cost of serving future requests. Subsequent work in Figliozzi, Mahmassani, and Jaillet (2005) studies the effect of bid learning mechanisms and auction settings on the performance of the transportation marketplace, highlighting the effect on market performance of the information known by the carriers at the time of bidding. More recently, Figliozzi, Mahmassani, and Jaillet (2006) introduce the concept of opportunity costs in truckload sequential auctions, propose an expression to quantify and approximate such opportunity costs, and discuss initial simulation results. In his doctoral dissertation, Figliozzi (2004) suggests a game-theoretic equilibrium formulation of the decision problems faced by the carriers (bidders) and, recognizing the intractability of that formulation, proposes a bounded rationality approach to study carriers' behavior and bidding. The present paper formalizes and further develops the ideas in Figliozzi's dissertation and in Figliozzi, Mahmassani, and Jaillet (2006) to present a precise treatment of the sequential pricing problem and its related behavioral and informational assumptions. Results related to the relative magnitude and impact of future profits in relation to static insertion costs are estimated and discussed. Finally, note that work related to combinatorial auctions (rather than the sequential bid decisions in the present work) in transportation can be found in Caplice (1996), Sheffi (2004), Song and Regan (2005), and Wang and Xia (2005).

The VRPCE introduced in this paper generalizes the TSPP to a dynamic environment, and presents a rigorous and precise treatment of the sequential pricing and costing problem that a carrier faces in a dynamic environment. The sequential pricing problem presented here is an intrinsic feature of a sequential auction problem, which also typically includes beyond pricing and costing, strategic game-theoretic elements that are needed to represent a general auction process.

\section{VRPCE Conceptual Description and Mathematical Framework}

The VRPCE is an extension of TSPP problems to a dynamic environment where customer arrivals/ characteristics have some degree of uncertainty and the service cost must be estimated before the carrier decides to serve or compete for an arriving request. There are five main characteristics of a VRPCE: (a) the vehicle routing problem is dynamic, i.e., service requests/contracts arrive over time; (b) there is a degree of uncertainty about customer requests, arrival times, and characteristics; (c) carriers must dynamically estimate the incremental cost or price of servicing a new request/contract; (d) each service provided has a monetary reward that is uncertain at the time of estimating the cost; and (e) the carrier's profit depends on the reward obtained and on how 
effectively the fleet is managed (service/travel costs or resources spent to service customers).

The VRPCE is a variation of the VRP because service costs are route and schedule dependent (a). The type of VRP (capacitated, with time windows, etc.) is not essential in the general formulation for the VRPCE presented in this paper, although it is highly relevant when the specific routing problems have to be solved (\$6). The problem is essentially dynamic and stochastic (b), otherwise the problem is a version of the already mentioned static TSPP. The accuracy needed to estimate service costs or prices (c) depends on whether the reward (d) to be obtained is known (acceptance/rejection problem) or unknown (cost/pricing problem). Known-reward problems can be easier to solve because establishing lower/upper bounds can be computationally simpler. Regarding rewards (e), the VRPCE is similar to the PTP, but the rewards are unknown for requests that have not been yet awarded (the rewards depend on competitors' prices as in second-price auctions).

Consider a carrier in a transportation marketplace where the carrier has to prevail in price to acquire the right to serve any given shipper. Shippers announce contracts on an ongoing basis. Each contract may consist of one or several shipments that the chosen carrier will have to serve; only one price can be submitted as a bid per contract. ${ }^{1}$

Let the contract arrival/announcement epochs be $\left\{t_{1}, t_{2}, \ldots, t_{N}\right\}$, such that $0<t_{1}$ and $t_{i}<t_{i+1}$. We assume that contracts are tendered and awarded in real time, thus precluding carriers from pricing more than one contract at the same time. Let $t_{j}$ represent the time when contract $s_{j}$ arrives and the carrier tenders a price $b_{j} \in R$, where $R$ is the set of real numbers. After each contract offering, the carrier receives feedback $y_{j}$ regarding the outcome of the offering. The public information known at the time of the offering for contract $s_{j}$ is $h_{j}=\left(h_{0}, y_{1}, y_{2}, \ldots, y_{j-1}\right)$, where $h_{0}$ denotes the information known by all carriers at time $t_{0}=0$ (with $t_{0}<t_{1}$ ) before bidding for contract $s_{1}$. Similarly, the information known at a time $t$ with $t_{j-1}<t \leq t_{j}$ is $h_{t}=\left(h_{0}, y_{1}, y_{2}, \ldots, y_{j-1}\right)$. Again, the information $h_{j+1}=\left(h_{0}, y_{1}, y_{2}, \ldots, y_{j-1}, y_{j}\right)$ is assumed known at any time $t$ with $t_{j}<t \leq t_{j+1}$, and so on. The amount and quality of feedback information received will depend on the particulars of the market rules, as discussed in $\S 7$.

Arrival times and contract characteristics are not known in advance. They are assumed to come

\footnotetext{
${ }^{1}$ The limitation is on one price for a contract as a whole, therefore disallowing contract splitting or combinatorial pricing. If a carrier cannot serve a contract as specified by the shipper-for example, a hard time window or other constraint that cannot be met due to previously won, but not yet served, contracts-the carrier does not participate in the tender.
}

from a probability space $(\Omega, \mathscr{F}, \mathscr{P})$, with outcomes $\left\{\omega_{1}, \omega_{2}, \ldots, \omega_{N}\right\}$. Any arriving contract $s_{j}$ represents a realization at time $t_{j}$ from the aforementioned probability space, therefore, $\omega_{j}=\left\{t_{j}, s_{j}\right\}$. Let $\left\{s_{1}, s_{2}, \ldots, s_{N}\right\}$ $=S$ be the set of arriving contracts. The number $N$ of future demand realizations considered by the carrier is the length of a finite rolling horizon ( $\mathrm{RH})$. A finite $\mathrm{RH}$ is adopted due to: (a) the intractability of the infinite-horizon problem and (b) the unreliability of demand and price forecasts associated with long time horizons, as discussed in $\$ 7 .^{2}$ The level of carrier competition is represented by a random variable $\xi$, whose successive realizations $\left(\xi_{j}\right)_{1 \leq j \leq N}$ represent the best prices offered by the competition and/or the reservation prices of the shippers, whichever is least, during the $N$ successive contract offerings. If a request or contract cannot be served and is rejected (all bids above the reservation price), the request is assumed to be served by alternative means. The carrier gains the right to serve contract $s_{j}$ if $b_{j}<\xi_{j}$; if $b_{j}=\xi_{j}$, contract $s_{j}$ is assumed to be awarded to the carrier with some known probability. ${ }^{3}$

A central assumption of this VRPCE formulation is that the carrier believes that the future level of contract price competition is not influenced by his past, present, or future actions (price or fleet management related). The market-clearing setup is equivalent to the clearing rules of a sequential second-price auction, so if the carrier wins the right to serve contract $s_{j}$, then this carrier is paid an amount $\xi_{j}$. There are no participation costs or penalties for losing an offering.

The fleet status at time $t$ is denoted as $z_{t}$, which comprises two different sets: the set of vehicles with their status updated to time $t$ and the set of contracts acquired, but not yet served, up to time $t$. The fleet status at time $t_{j}$ when contract $s_{j}$ arrives will be denoted as $z_{j}$. Note that the set $z_{j}$ does not include information on the just-arrived contract $s_{j}$. Let $I_{j}$ be the indicator variable for shipment $s_{j}$, such that $I_{j}=1$ if the carrier has secured the offering for contract $s_{j}$ and $I_{j}=0$ otherwise. As contracts are tendered and awarded in real time, the status of the fleet updated with the tender result is denoted $z_{j} \mid I_{j}$. To shorten notation, a superscript " 1 " will indicate that the contract was won; a superscript " 0 " indicates that the contract was lost. Then, the updated states are $z_{j}^{1}=z_{j} \mid$ $\left(I_{j}=1\right)$ and $z_{j}^{0}=z_{j} \mid\left(I_{j}=0\right)$, respectively. If a carrier is

\footnotetext{
${ }^{2}$ The carrier's optimal choice of $N$ must balance the costs associated with data collection, computation, and forecasting reliability. This is a complex problem in itself, and beyond the scope of this paper. Alternatively, $N$ could be determined by a limit imposed on the time horizon length, i.e., a carrier must return to the depot after a predetermined number of working hours.

${ }^{3}$ This probability will depend on market settings such as the number of competitors and the shipper's policy regarding the assignment of contracts when the reservation price is met.
} 
submitting a tender for contract $s_{j}$ at time $t_{j}$, the symbol "-" is used to represent the previous successful tender as time $t_{j-}$ (the last tender won by the carrier before time $t_{j}$ ). For the particular case of $s_{1}$ or for a carrier with no wins up to time $t_{j}$, we use $t_{0}$ as the previous successful tender. The updated fleet status immediately after winning the contract that arrived at time $t_{j-}$ is denoted $z_{j-}^{1}$; in particular if $t_{j-}=t_{0}$ then $z_{j-}^{1}=z_{0}$.

It is assumed that the fleet status at a given time is a function of time, previous fleet status, and history up to the previous epoch; travel and service times are assumed to be deterministic. This can be expressed by assuming the existence of a state or assignment function, ${ }^{4}$ such that the status of the carrier when shipment $s_{j}$ arrives is $z_{j}=\mathrm{a}\left(t_{j}, h_{j}, z_{j-1}\right)$, or in general $z_{t}=$ $\mathrm{a}\left(t, h_{t}, z_{j}\right)$ for any $t_{j}<t \leq t_{j+1}$.

The distance or cost incurred by the fleet from time $t_{j}$ up to time $t$ using assignment function "a" with initial status $z_{j}^{1}$ is denoted $\mathrm{d}\left(\mathrm{a}, z_{j}^{1}, t\right)$. Let $t_{j}^{\prime}$ be the time at which the carrier completely serves all the contracts in $z_{j}^{1}$. Because distance (or time) costs cannot be negative, it follows that $d\left(a, z_{j}^{1}, t\right)$ is a nondecreasing function. It also has constant values on the following ranges:

$$
\begin{aligned}
& \text { - for } t<t_{j}, \mathrm{~d}\left(\mathrm{a}, z_{j}^{1}, t\right)=0, \\
& \text { - for } t>t_{j}^{\prime}, \mathrm{d}\left(\mathrm{a}, z_{j}^{1}, t\right)=\mathrm{d}\left(\mathrm{a}, z_{j}^{1}, t_{j}^{\prime}\right) .
\end{aligned}
$$

At time $t_{j}$, the incremental cost of serving contract $s_{j}$ up to time $t \geq t_{j}$ is estimated using: $c\left(s_{j}, t\right)=$ $\mathrm{d}\left(\mathrm{a}, z_{j}^{1}, t\right)-\left\{\mathrm{d}\left(\mathrm{a}, z_{j-}^{1}, t\right)-\mathrm{d}\left(\mathrm{a}, z_{j-}^{1}, t_{j}\right)\right\}$. The VRPCE consists of determining the price for each arriving shipment $s_{j}$; this problem is analyzed in the next section.

\section{The VRPCE}

The VRPCE can be formulated as a stochastic dynamic programming problem where each stage is defined by the arrival of a new contract, price is the decision variable, and the state transitions are determined by the contract award and fleet assignment processes. In this section we assume that a fleet deployment process can only be changed or interrupted by winning a new contract. In particular, at time $t_{j}$, the full incremental cost of serving contract $s_{j}$ is denoted as ${ }^{5}$

$$
\begin{aligned}
c\left(s_{j}\right) & =c\left(s_{j}, t_{j}^{\prime}\right)=\mathrm{d}\left(\mathrm{a}, z_{j}^{1}, t_{j}^{\prime}\right)-\left\{\mathrm{d}\left(\mathrm{a}, z_{j-}^{1}, t_{j}^{\prime}\right)-\mathrm{d}\left(\mathrm{a}, z_{j-}^{1}, t_{j}\right)\right\} \\
& =\mathrm{d}\left(\mathrm{a}, z_{j}^{1}, t_{j}^{\prime}\right)-\mathrm{d}\left(\mathrm{a}, z_{j}^{0}, t_{j}^{\prime}\right) .
\end{aligned}
$$

${ }^{4}$ The assignment function is problem dependent; it can be any algorithm that the carrier uses to solve the corresponding routing problem and to estimate future fleet status.

${ }^{5}$ In general, earlier deployment schedules with fewer contracts finish earlier. It is assumed without loss of generality that $t_{j}^{\prime} \geq t_{j^{-}}^{\prime}$, the completion time of $t_{j}^{\prime}$ stochastically dominates $t_{j^{-}}^{\prime}$, otherwise this expression should be used with $t_{j}^{\prime}$ replaced by $t_{j}^{\prime}=\max \left(t_{j}^{\prime}, t_{j^{-}}^{\prime}\right)$.
Because the VRPCE is a stochastic dynamic programming problem, we could solve it using backward induction. The carrier pricing the last contract $s_{N}$ at time $t_{N}$ is in a situation strategically similar to a oneitem second-price auction because: (a) the carrier's reward depends on the realization of the price competition for contract $s_{j}$, which is $\xi_{j}$; (b) this reward $\xi_{j}$ is independent of any action taken by the carrier; and (c) the carrier wins the right to serve contract $s_{j}$ if $b_{j}<\xi_{j}$. If $b_{j}=\xi_{j}$, the right to serve the contract is obtained with a known probability dependent on market settings, but independent of the value $b_{j}$.

In a one-item second-price auction, the value of the item (to a particular bidder) is a weakly dominant strategy. This value (cost in a reverse auction) is the bid that maximizes the bidder's expected profit (Vickrey 1961). Applying this logic to a reverse auction in the VRPCE setting, the cost of the contract is a weakly dominant strategy. This cost is the price that maximizes the carrier's expected profit. Therefore, the price for $s_{N}$ that maximizes the carrier's expected profit is $b_{N}^{*}=c\left(s_{N}\right)$. Note that at time $t_{N}$ the effect of previous actions $\left\{b_{1}, \ldots, b_{N-1}\right\}$ is summarized in the state variable $z_{N}^{0}$, i.e., the cost of previous actions in the time interval $\left\{t_{1}, \ldots, t_{N}\right\}$ is already a "sunk" cost and should not be considered again at time $t_{N}$.

The carrier pricing the contract $s_{N-1}$ is not in a situation strategically similar to a one-item secondprice auction because the submitted price $b_{N-1}$ has an impact on the future status of the carrier at time $t_{N}$, and therefore may affect the profit obtained for contract $s_{N}$. After submitting $b_{N-1}$ there are only two possible outcomes: (1) the rights for contract $s_{N-1}$ are acquired; or (2) the rights are lost. If the former is true, the carrier's status at time $t_{N}$ will be $z_{N} \mid z_{N-1}^{1}=$ $\mathrm{a}\left(t_{N}, h_{N}, z_{N-1}^{1}\right)$. If the latter is true, the carrier's status at time $t_{N}$ will be $z_{N} \mid z_{N-1}^{0}=\mathrm{a}\left(t_{N}, h_{N}, z_{N-1}^{0}\right)$. Defining $\pi_{N}\left(s_{N} \mid z_{N-1}^{I_{N-1}}\right)$ as the expected profits from contract $s_{N}$ conditional on the previous outcome as

$$
\begin{aligned}
\pi_{N}\left(s_{N} \mid z_{N-1}^{1}\right) & =\pi_{N}\left(s_{N} \mid I_{N-1}=1\right) \\
& =E_{\left(\omega_{N}\right)}\left[E_{(\xi)}\left[\left(\xi-c\left(s_{N}\right) \mid z_{N-1}^{1}\right) I_{N}\right]\right] \\
I_{N} & =1 \quad \text { if } \xi>b_{N}^{*} \mid I_{N-1}=1 \quad \text { and } \\
I_{N} & =0 \quad \text { if } \xi<b_{N}^{*} \mid I_{N-1}=1
\end{aligned}
$$

or

$$
\begin{aligned}
& \pi_{N}\left(s_{N} \mid z_{N-1}^{0}\right)= \pi_{N}\left(s_{N} \mid I_{N-1}=0\right) \\
&= E_{\left(\omega_{N}\right)}\left[E_{(\xi)}\left[\left(\xi-\mathrm{c}\left(s_{N}\right) \mid z_{N-1}^{0}\right) I_{N}\right]\right] \\
& I_{N}=1 \quad \text { if } \xi>b_{N}^{*} \mid I_{N-1}=0 \quad \text { and } \\
& I_{N}=0 \quad \text { if } \xi<b_{N}^{*} \mid I_{N-1}=0 .
\end{aligned}
$$

If contract $s_{N-1}$ is acquired, the carrier's fleet will not necessarily travel a distance equivalent to the 
myopic incremental cost $c\left(s_{N-1}\right)$ because the possible arrival and acquisition of contract $s_{N}$ may cut short the fleet's deployment plan, implemented at time $t_{N-1}$. The optimal price $b_{N-1}^{*}$ that maximizes the carrier's expected profits from time $t_{N-1}$ onward is

$$
\begin{aligned}
b_{N-1}^{*} \in \operatorname{argmax} E_{(\xi)} & {\left[\left(\xi-c\left(s_{N-1}\right)\right) I_{N-1}+\pi_{N}\left(s_{N} \mid z_{N-1}^{1}\right) I_{N-1}\right.} \\
& \left.+\pi_{N}\left(s_{N} \mid z_{N-1}^{0}\right)\left(1-I_{N-1}\right)\right],
\end{aligned}
$$

$b \in R, \quad I_{N-1}=1$ if $\xi>b$ and $I_{N-1}=0$ if $\xi<b$.

Similarly, after submitting $b_{N-2}$ there are only two possible outcomes: (1) the rights for contract $s_{N-2}$ are acquired, or (2) the rights are lost. If the former is true, the carrier's status at time $t_{N-1}$ will be $z_{N-1}$ | $z_{N-2}^{1}$. If the latter is true, the carrier's status at time $t_{N-1}$ will be $z_{N-1} \mid z_{N-2}^{0}$. Defining $\pi_{N-1}\left(s_{N-1} \mid z_{N-2}^{I_{N-2}}\right)$ as the expected profits from contract $s_{N-1}$ onward conditional on the previous outcome as

$$
\begin{gathered}
\pi_{N-1}\left(s_{N-1} \mid z_{N-2}^{1}\right) \\
=E_{\left(\omega_{N-1}\right)}\left[E _ { ( \xi ) } \left[\left(\xi-c\left(s_{N-1}\right) \mid z_{N-2}^{1}\right) I_{N-1}+\pi_{N}\left(s_{N} \mid z_{N-1}^{1}\right) I_{N-1}\right.\right. \\
\left.\left.+\pi_{N}\left(s_{N} \mid z_{N-1}^{0}\right)\left(1-I_{N-1}\right)\right]\right] \\
I_{N-1}=1 \quad \text { if } \xi>b_{N-1}^{*} \mid I_{N-2}=1 \quad \text { and } \\
I_{N-1}=0 \quad \text { if } \xi<b_{N-1}^{*} \mid I_{N-2}=1
\end{gathered}
$$

and

$$
\begin{gathered}
\pi_{N-1}\left(s_{N-1} \mid z_{N-2}^{0}\right) \\
=E_{\left(\omega_{N-1}\right)}\left[E _ { ( \xi ) } \left[\left(\xi-c\left(s_{N-1}\right) \mid z_{N-2}^{0}\right) I_{N-1}+\pi_{N}\left(s_{N} \mid z_{N-1}^{1}\right) I_{N-1}\right.\right. \\
\left.\left.+\pi_{N}\left(s_{N} \mid z_{N-1}^{1}\right)\left(1-I_{N-1}\right)\right]\right] \\
I_{N-1}=1 \quad \text { if } \xi>b_{N-1}^{*} \mid I_{N-2}=0 \text { and } \\
I_{N-1}=0 \quad \text { if } \xi<b_{N-1}^{*} \mid I_{N-2}=0 .
\end{gathered}
$$

Note (again) that at time $t_{N-1}$ the effect of previous actions $\left\{b_{1}, \ldots, b_{N-2}\right\}$ is summarized in the state variable $z_{N-1}^{0}$, i.e., the cost of previous actions in the time interval $\left\{t_{1}, \ldots, t_{N-1}\right\}$ is already a sunk cost and should not be considered again at time $t_{N-1}$. The optimal price $b_{N-2}^{*}$ that maximizes the carrier's expected profits from time $t_{N-2}$ onward is

$$
\begin{array}{r}
b_{N-2}^{*} \in \arg \max E_{(\xi)}\left[\left(\xi-c\left(s_{N-2}\right)\right) I_{N-2}+\pi_{N-1}\left(s_{N-1} \mid z_{N-2}^{1}\right)\right. \\
\left.\cdot I_{N-2}+\pi_{N-1}\left(s_{N-1} \mid z_{N-2}^{0}\right)\left(1-I_{N-2}\right)\right]
\end{array}
$$$$
b \in R, \quad I_{N-2}=1 \text { if } \xi>b \text { and } I_{N-2}=0 \text { if } \xi<b \text {. }
$$

Using induction, the optimal price $b_{j}^{*}$ that maximizes the carrier's expected profits from time $t_{j}$ onward is

$$
\begin{array}{r}
b_{j}^{*} \in \arg \max E_{(\xi)}\left[\left(\xi-c\left(s_{j}\right)\right) I_{j}+\pi_{j+1}\left(s_{j+1} \mid z_{j}^{1}\right) I_{j}\right. \\
\left.+\pi_{j+1}\left(s_{j+1} \mid z_{j}^{0}\right)\left(1-I_{j}\right)\right]
\end{array}
$$

$b \in R, \quad I_{j}=1 \quad$ if $\xi>b$ and $I_{j}=0$ if $\xi<b$ where $\pi_{j+1}\left(s_{j+1} \mid z_{j}^{I_{j}}\right)$ is defined as the expected profits from contract $s_{j+1}$ onward and conditional on the previous outcome as

$$
\begin{gathered}
\pi_{j+1}\left(s_{j+1} \mid z_{j}^{1}\right) \\
=E_{\left(\omega_{j+1}\right)}\left[E _ { ( \xi ) } \left[\left(\xi-c\left(s_{j+1}\right) \mid z_{j}^{1}\right) I_{j+1}+\pi_{j+2}\left(s_{j+2} \mid z_{j+1}^{1}\right) I_{j+1}\right.\right. \\
\left.\left.+\pi_{j+2}\left(s_{j+2} \mid z_{j+1}^{0}\right)\left(1-I_{j+1}\right)\right]\right] \\
I_{j+1}=1 \quad \text { if } \xi>b_{j+1}^{*} \mid I_{j}=1 \text { and } \\
I_{j+1}=0 \quad \text { if } \xi<b_{j+1}^{*} \mid I_{j}=1
\end{gathered}
$$

and

$$
\begin{gathered}
\pi_{j+1}\left(s_{j+1} \mid z_{j}^{0}\right) \\
=E_{\left(\omega_{j+1}\right)}\left[E _ { ( \xi ) } \left[\left(\xi-c\left(s_{j+1}\right) \mid z_{j}^{0}\right) I_{j+1}+\pi_{j+2}\left(s_{j+2} \mid z_{j+1}^{1}\right) I_{j+1}\right.\right. \\
\left.\left.+\pi_{j+2}\left(s_{j+2} \mid z_{j+1}^{0}\right)\left(1-I_{j+1}\right)\right]\right] \\
I_{j+1}=1 \quad \text { if } \xi>b_{j+1}^{*} \mid I_{j}=0 \quad \text { and } \\
I_{j+1}=0 \quad \text { if } \xi<b_{j+1}^{*} \mid I_{j}=0 .
\end{gathered}
$$

\subsection{Solving for the Optimal Price in the VRPCE}

Neither Equation (2) nor Equation (3) is affected by the bid value for shipment $s_{j}$; they are simply conditioned on the outcome of the tender for $s_{j}$. The expected value of the present plus future profits for any bid $b \in R$ can be expressed as

$$
\begin{aligned}
& E_{(\xi)}\left[\left(\xi-c\left(s_{j}\right)\right) I_{j}+\pi_{j+1}\left(s_{j+1} \mid z_{j}^{1}\right) I_{j}+\pi_{j+1}\left(s_{j+1} \mid z_{j}^{0}\right)\left(1-I_{j}\right)\right] \\
& =\int_{b}^{\infty}\left(\xi-c\left(s_{j}\right)\right) p(\xi) d(\xi)+\int_{b}^{\infty} \pi_{j+1}\left(s_{j+1} \mid z_{j}^{1}\right) p(\xi) d(\xi) \\
& \quad+\int_{-\infty}^{b} \pi_{j+1}\left(s_{j+1} \mid z_{j}^{0}\right) p(\xi) d(\xi) .
\end{aligned}
$$

The first two integrals are evaluated in the interval $[b, \infty]$ because they equal zero as long as price $b$ is greater than the competitors' prices, or equivalently, if the contract $s_{j}$ is lost. The last integral is evaluated in the interval $[-\infty, b]$ because it is zero only when the bid $b$ is smaller than the competitors' bids, or equivalently, if the contract $s_{j}$ is won. ${ }^{6}$ Grouping terms in (4):

$$
\begin{aligned}
& \int_{b}^{\infty}\left(\xi-c\left(s_{j}\right)\right) p(\xi) d(\xi)+\int_{b}^{\infty} \pi_{j+1}\left(s_{j+1} \mid z_{j}^{1}\right) p(\xi) d(\xi) \\
& \quad+\int_{-\infty}^{b} \pi_{j+1}\left(s_{j+1} \mid z_{j}^{0}\right) p(\xi) d(\xi) \\
& =\int_{b}^{\infty}\left(\xi-c\left(s_{j}\right)+\pi_{j+1}\left(s_{j+1} \mid z_{j}^{1}\right)-\pi_{j+1}\left(s_{j+1} \mid z_{j}^{0}\right)\right) p(\xi) d(\xi) \\
& \quad+\int_{-\infty}^{\infty} \pi_{j+1}\left(s_{j+1} \mid z_{j}^{0}\right) p(\xi) d(\xi) .
\end{aligned}
$$

${ }^{6}$ Appendix 1 considers the case where $p(b=\xi)$ is not negligible (e.g., the price function is a probability mass function). The derivation is somewhat different, but the optimal price has the same expression in both cases. 
The term

$$
-c\left(s_{j}\right)+\pi_{j+1}\left(s_{j+1} \mid z_{j}^{1}\right)-\pi_{j+1}\left(s_{j+1} \mid z_{j}^{0}\right)
$$

does not depend on the realization of $\xi$ or the value of $b$. Denoting $c_{j}^{*}=c\left(s_{j}\right)-\pi_{j+1}\left(s_{j+1} \mid z_{j}^{1}\right)+\pi_{j+1}\left(s_{j+1} \mid z_{j}^{0}\right)$ and replacing in (4):

$$
\begin{gathered}
E_{(\xi)}\left[\left(\xi-c\left(s_{j}\right)\right)+\pi_{j+1}\left(s_{j+1} \mid z_{j}^{1}\right)+\pi_{j+1}\left(s_{j+1} \mid z_{j}^{0}\right)\right] \\
=\pi_{j+1}\left(s_{j+1} \mid z_{j}^{0}\right)+\int_{b}^{\infty}\left(\xi-c_{j}^{*}\right) p(\xi) d(\xi) .
\end{gathered}
$$

Equation (6) is strategically equivalent to a secondprice auction, where $\xi$ represents the distribution of the best competitors' prices and $c_{j}^{*}$ is the carrier's cost. The price that maximizes Equation (6) is simply $c_{j}^{*}$; the proof that $c_{j}^{*}$ is optimal parallels the proof for the one-item second-price auction. Assuming $b>c_{j}^{*}$, then

$$
\begin{aligned}
\int_{b}^{\infty}\left(\xi-c_{j}^{*}\right) p(\xi) d(\xi) \leq & \int_{b}^{\infty}\left(\xi-c_{j}^{*}\right) p(\xi) d(\xi) \\
& +\int_{c_{j}^{*}}^{b}\left(\xi-c_{j}^{*}\right) p(\xi) d(\xi) \\
= & \int_{c_{j}^{*}}^{\infty}\left(\xi-c_{j}^{*}\right) p(\xi) d(\xi)
\end{aligned}
$$

because all the elements in the last integral are equal or larger than zero. Assuming $b<c_{j}^{*}$, then

$$
\begin{aligned}
\int_{c_{j}^{*}}^{\infty}\left(\xi-c_{j}^{*}\right) p(\xi) d(\xi) \geq & \int_{c_{j}^{*}}^{\infty}\left(\xi-c_{j}^{*}\right) p(\xi) d(\xi) \\
& +\int_{b}^{c_{j}^{*}}\left(\xi-c_{j}^{*}\right) p(\xi) d(\xi) \\
= & \int_{b}^{\infty}\left(\xi-c_{j}^{*}\right) p(\xi) d(\xi)
\end{aligned}
$$

because in the last integral the term $\xi-c_{j}^{*}$ is negative, whereas the other multiplicands are equal to or larger than zero. Therefore, Equation (6) is maximized when $b=c_{j}^{*}$, so the optimal bid for a shipment $s_{j}$ is

$$
c_{j}^{*}=c\left(s_{j}\right)-\pi_{j+1}\left(s_{j+1} \mid z_{j}^{1}\right)+\pi_{j+1}\left(s_{j+1} \mid z_{j}^{0}\right) .
$$

In a one-item second-price auction, the optimal bid is equivalent to the value of the item, at a price such that the bidder is indifferent between accepting or rejecting the item. Applying the same logic, a carrier's cost of serving a contract is equal to the price that maximizes the carrier's profit-in the assumed marketplace and given a carrier's assignment function and status-the value is provided by Equation (7). Equations (2) and (3) show the recursive and exponential nature of the problem. The assignment function $z_{t}=\mathrm{a}\left(t, h_{t}, z_{j-1}\right)$ is the rule used to obtain a carrier's status when a new shipment arrives, or a projection of a schedule into the future. The cost provided by $c\left(s_{j}\right)$ is the incremental cost for incorporating $s_{j}$ into the carrier schedule. Equation (7) represents the value of the best price for a contract given a carrier's assignment technology "a." Therefore, a carrier with a different fleet assignment method may have a different value for the optimal bid (even if both carriers have the same fleet status). The intuition behind (7) is straightforward. The first term represents the "incremental cost" of serving contract $s_{j}$. The other two terms are linked to the future and are best interpreted together as the change in future profits or opportunity costs brought about by serving contract $s_{j}$. This is illustrated in a simple example in the next section.

\section{VRPCE Example}

This section illustrates how the concepts and formulas derived in $\$ 3$ apply to a simple yet instructive example. Consider a single truck that serves a square region $A B C D$. Only two types of contracts are possible: carrying a load from $A$ to $B$ (contract $A B$ ) or from $D$ to $A$ (contract $D A$ ), as illustrated in Figure 1 . A contract arrives at each unit of time; there are no uncertainties about the arrival times, only about the contract characteristics, $\Omega=\{A B, D A\}$ and $p(A B)=$ $p(D A)=0.5$. The distances are Manhattan (metric 1), and there are no repositioning costs associated with the final location of the truck. Each contract must be fully served within three units of time following its arrival (time window). The truck travels with a unit speed; therefore, in a unit of time the truck covers a distance equivalent to a side of the square. There is a probability mass function for the "competition prices:" $p(\xi=1)=1 / 4, p(\xi=2)=1 / 2$, and $p(\xi=3)=$ $1 / 4$. The carrier assignment function is such that the truck travels the shortest path necessary to serve all outstanding (not yet fully served) contracts. The execution of a shortest path (deployment plan) can only
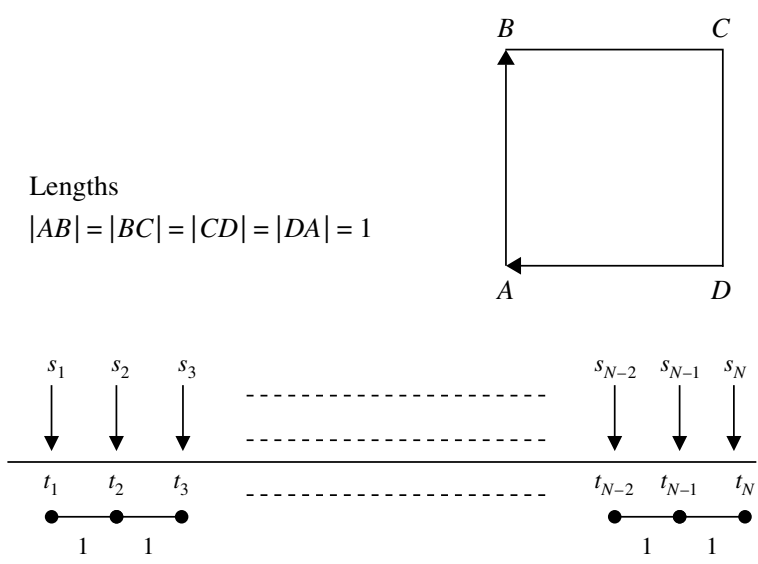

Figure 1 Example: Square Service Region, Two Types of Contracts, and Constant Deterministic Contract Arrival Rate 
be interrupted or modified by the acquisition of future contracts.

To illustrate the concepts and formulas, let us initially assume that the truck is located at vertex $A$ at time $t_{N}$ and has no outstanding (remaining) contracts to serve. If contract $A B$ arrives at time $t_{N}$ and the carrier status is $z_{N}=\{A\}$, the price is simply the full incremental cost $b_{N}\left(s_{N}=A B\right)=1$; for contract $D A$ and $z_{N}=\{A\}$ the price is simply $b_{N}\left(s_{N}=D A\right)=2$.

Assume that the truck is located at vertex $A$ at time $t_{N-1}$ and has no outstanding (remaining) contracts to serve with corresponding $z_{N-1}=\{A\}$. If contract $A B$ arrives at time $t_{N-1}$ and the carrier status is $z_{N-1}=\{A\}$, the price is

$$
\begin{aligned}
b_{N-1}\left(s_{N-1}=A B\right)= & c\left(s_{N-1}\right)-\pi_{N}\left(s_{N} \mid z_{N-1}^{1}\right) \\
& +\pi_{N}\left(s_{N} \mid z_{N-1}^{0}\right) .
\end{aligned}
$$

The incremental cost in this case is

$$
\begin{aligned}
c\left(s_{N-1}=A B\right) & =\mathrm{d}\left(\mathrm{a}, z_{N-1}^{1}, t_{N-1}^{\prime}\right)-\mathrm{d}\left(\mathrm{a}, z_{N-1}^{0}, t_{N-1}^{\prime}\right) \\
& =1-0=1 .
\end{aligned}
$$

The term $\pi_{N}\left(s_{N} \mid z_{N-1}^{1}\right)$ is calculated, taking into account that $z_{N-1}^{1}=\{A, A B\}$ and the future status is going to be $z_{N}=\{B\}$, then $\mathrm{c}\left(s_{N}=A B\right) \mid\left(z_{N}=\{B\}\right)=2$ and $\mathrm{c}\left(s_{N}=D A\right) \mid\left(z_{N}=\{B\}\right)=3$. For the case where $c\left(s_{N}=A B\right) \mid\left(z_{N}=\{B\}\right)=2=b_{N}$, the expected profit at time $t_{N}$ is calculated as

$$
\begin{aligned}
& E_{(\xi)}\left[\left(\xi-c\left(s_{N}=A B\right) \mid\left(z_{N}=\{B\}\right)\right) I_{N}\right] \\
& \quad=E_{(\xi)}\left[\left(\xi-b_{N} \mid\left(z_{N}=\{B\}\right)\right) I_{N}\right]=(3-2) 1 / 4=1 / 4 .
\end{aligned}
$$

Only one term is needed, because the arrival of contract $s_{N}$ will not produce any profits for price realizations $\xi \leq b_{N}=2=\mathrm{c}\left(s_{N}=A B\right) \mid\left(z_{N}=\{B\}\right)$. For the case where $c\left(s_{N}=D A\right) \mid\left(z_{N}=\{B\}\right)=3=b_{N}$, the expected profit at time $t_{N}$ is simply zero because all possible prices are less than or equal to three. The term $\pi_{N}\left(s_{N} \mid z_{N-1}^{1}\right)$ is then estimated as

$$
\begin{aligned}
\pi_{N}\left(s_{N} \mid z_{N-1}^{1}\right) & =E_{\left(\omega_{N}\right)}\left[E_{(\xi)}\left[\left(\xi-c\left(s_{N}\right) \mid z_{N-1}^{1}\right) I_{N}\right]\right] \\
& =(1 / 2)(1 / 4)=1 / 8 .
\end{aligned}
$$

The term $\pi_{N}\left(s_{N} \mid z_{N-1}^{0}\right)$ is calculated, taking into account that $z_{N-1}^{0}=\{A\}$ and the future status is going to be $z_{N}=\{A\}$; then $\mathrm{c}\left(s_{N}=A B \mid z_{N}=\{A\}\right)=1=b_{N}$ and $\mathrm{c}\left(s_{N}=D A \mid z_{N}=\{A\}\right)=2=b_{N}$. For the former cost the expected profit is

$$
\begin{array}{r}
E_{(\xi)}\left[\left(\xi-c\left(s_{N}=A B \mid z_{N}=\{A\}\right)\right) I_{N}\right] \\
=(3-1) 1 / 4+(2-1) 1 / 2=1 .
\end{array}
$$

For the latter cost the expected profit is

$$
E_{(\xi)}\left[\left(\xi-c\left(s_{N}=D A \mid z_{N}=\{A\}\right)\right) I_{N}\right]=(3-2) 1 / 4=1 / 4 .
$$

The term $\pi_{N}\left(s_{N} \mid z_{N-1}^{0}\right)$ is estimated as

$$
\begin{aligned}
\pi_{N}\left(s_{N} \mid z_{N-1}^{1}\right) & =E_{\left(\omega_{N}\right)}\left[E_{(\xi)}\left[\left(\xi-\mathrm{c}\left(s_{N}\right) \mid z_{N-1}^{0}\right) I_{N}\right]\right] \\
& =(1 / 2) 1+(1 / 2)(1 / 4)=5 / 8 .
\end{aligned}
$$

The optimal price for $s_{N-1}=A B$ with $z_{N-1}=\{A\}$ is calculated as

$$
\begin{aligned}
b_{N-1}\left(s_{N-1}=A B\right) & =c\left(s_{N-1}\right)-\pi_{N}\left(s_{N} \mid z_{N-1}^{1}\right)+\pi_{N}\left(s_{N} \mid z_{N-1}^{0}\right) \\
& =1-1 / 8+5 / 8=3 / 2 .
\end{aligned}
$$

Assume that the truck is located at vertex $A$ at time $t_{N-1}$ with $z_{N-1}=\{A\}$. If contract $D A$ has arrived at time $t_{N-1}$ and the carrier status is $z_{N-1}=\{A\}$, the price is

$b_{N-1}\left(s_{N-1}=D A\right)=c\left(s_{N-1}\right)-\pi_{N}\left(s_{N} \mid z_{N-1}^{1}\right)+\pi_{N}\left(s_{N} \mid z_{N-1}^{0}\right)$.

The incremental cost in this case is obtained using

$$
\begin{aligned}
& c\left(s_{N-1}=D A \mid z_{N-1}=\{A\}\right) \\
& \quad=\mathrm{d}\left(\mathrm{a}, z_{N-1}^{1}, t_{N-1}^{\prime}\right)-\mathrm{d}\left(\mathrm{a}, z_{N-1}^{0}, t_{N-1}^{\prime}\right)=2-0=2 .
\end{aligned}
$$

The term $\pi_{N}\left(s_{N} \mid z_{N-1}^{1}\right)$ is calculated taking into account that $z_{N-1}^{1}=\{A ; D A\}$ and the future status is going to be $z_{N}=\{D ; D A\}$. In the case where there is an outstanding contract, the incremental cost of serving a just-arrived contract $s_{N}$ up to time $t \geq t_{N}$ is estimated using

$$
c\left(s_{N}, t\right)=\mathrm{d}\left(\mathrm{a}, z_{N}^{1}, t_{N}^{\prime}\right)-\mathrm{d}\left(\mathrm{a}, z_{N}^{0}, t_{N}^{\prime}\right),
$$

but the second term is not zero. In particular, for $\mathrm{c}\left(s_{N}=A B \mid z_{N}=\{D ; D A\}\right)$ and $c\left(s_{N}=D A \mid z_{N}=\right.$ $\{D ; D A\})$, the incremental costs for the last arriving contract are calculated as follows:

$$
\begin{aligned}
c\left(s_{N}\right. & \left.=A B \mid z_{N}=\{D, D A\}\right) \\
& =\mathrm{d}\left(\mathrm{a}, z_{N}^{1}, t_{N}^{\prime}\right)-\mathrm{d}\left(\mathrm{a}, z_{N}^{0}, t_{N}^{\prime}\right)=2-1=1 \\
c\left(s_{N}\right. & \left.=D A \mid z_{N}=\{D, D A\}\right) \\
& =\mathrm{d}\left(\mathrm{a}, z_{N}^{1}, t_{N}^{\prime}\right)-\mathrm{d}\left(\mathrm{a}, z_{N}^{0}, t_{N}^{\prime}\right)=1-1=0 .
\end{aligned}
$$

In the last expression it is implicitly assumed that the truck capacity is sufficient to carry two contract cargos simultaneously. The future expected profits are

$$
\begin{gathered}
E_{(\xi)}\left[\left(\xi-\mathrm{c}\left(s_{N}=A B \mid z_{N}=\{D ; D A\}\right)\right) I_{N}\right] \\
=(3-1) 1 / 4+(2-1) 1 / 2=1 \\
E_{(\xi)}\left[\left(\xi-c\left(s_{N}=D A \mid z_{N}=\{D ; D A\}\right)\right) I_{N}\right] \\
=(3-0) 1 / 4+(2-0) 1 / 2+(1-0)(1 / 4)=2 .
\end{gathered}
$$

The term $\pi_{N}\left(s_{N} \mid z_{N-1}^{1}\right)$ is estimated as

$$
\begin{aligned}
\pi_{N}\left(s_{N} \mid z_{N-1}^{1}\right) & =E_{\left(\omega_{N}\right)}\left[E_{(\xi)}\left[\left(\xi-c\left(s_{N}\right) \mid z_{N-1}^{1}\right) I_{N}\right]\right] \\
& =(1 / 2) 1+(1 / 2) 2=3 / 2 .
\end{aligned}
$$


The term $\pi_{N}\left(s_{N} \mid z_{N-1}^{0}\right)$ is calculated taking into account that $z_{N-1}^{0}=\{A\}$ and the future status is going to be $z_{N}=\{A\}$, then $\mathrm{c}\left(s_{N}=A B \mid z_{N}=\{A\}\right)=1$ and $\mathrm{c}\left(s_{N}=D A \mid z_{N}=\{A\}\right)=2$. For the former cost the expected profit is

$$
E_{(\xi)}\left[\left(\xi-\mathrm{c}\left(s_{N}=A B\right)\right) I_{N}\right]=(3-1) 1 / 4+(2-1) 1 / 2=1 .
$$

For the latter cost the expected profit is

$$
E_{(\xi)}\left[\left(\xi-c\left(s_{N}=D A\right)\right) I_{N}\right]=(3-2) 1 / 4=1 / 4 .
$$

The term $\pi_{N}\left(s_{N} \mid z_{N-1}^{0}\right)$ is then estimated as

$$
\begin{aligned}
\pi_{N}\left(s_{N} \mid z_{N-1}^{1}\right) & =E_{\left(\omega_{N}\right)}\left[E_{(\xi)}\left[\left(\xi-\mathrm{c}\left(s_{N}\right) \mid z_{N-1}^{0}\right) I_{N}\right]\right] \\
& =(1 / 2) 1+(1 / 2)(1 / 4)=5 / 8 .
\end{aligned}
$$

Then, the optimal price for $s_{N-1}=A B$ with $z_{N-1}=\{A\}$ is calculated as

$$
\begin{aligned}
b_{N-1}\left(s_{N-1}=A B\right) & =\bar{c}\left(s_{N-1}\right)-\pi_{N}\left(s_{N} \mid z_{N-1}^{1}\right)+\pi_{N}\left(s_{N} \mid z_{N-1}^{0}\right) \\
& =2-3 / 2+5 / 8=9 / 8 .
\end{aligned}
$$

This simple example illustrates the importance of properly estimating contract costs in a VRPCE environment. Obviously, contract $A B$ deploys the truck in an unfavorable position, whereas contract $D A$ deploys the truck in a highly favorable position. This is reflected in the prices starting from point $A$ and with no outstanding contracts: $b_{N}\left(s_{N}=A B\right)=1$ and $b_{N-1}\left(s_{N-1}=A B\right)=3 / 2$ (price goes up); $b_{N}\left(s_{N}=\right.$ $D A)=2$ and $b_{N-1}\left(s_{N-1}=D A\right)=9 / 8$ (price goes down). Not only is the price change sign different, but also the magnitude of the change is such that there is an order reversal if contracts are sorted (ascending or descending price order) at times $t_{N-1}$ and $t_{N}$.

This example also shows the importance of opportunity costs. There are two elements that could increase the appeal of serving contract $D A$ over contract $A B$ : (1) better deployment that reduces future incremental costs, and (2) the fact that two contracts can be served simultaneously. Note that in all cases the location of the truck was assumed to be at the same vertex $A$ initially. Appendix 3 shows the application of first-price auction payment rules to the same example; the results are remarkably different as illustrated in the next section and Appendix 3.

\section{Other Payment Mechanisms}

Altering the payment rules can significantly simplify or complicate the pricing problem. The former situation occurs if the reward for contract $s_{j}$ becomes known at the time of arrival; the latter situation occurs if the reward is a function of the submitted price. These two situations are described next.

\subsection{Acceptance/Rejection Problems}

If the reward for contract $s_{j}$ becomes known at the time of arrival, then the VRPCE problem becomes a dynamic acceptance/rejection problem. Let us denote $\xi_{j}$ as the reward for contract $s_{j}$. Equation (1) can be transformed into an acceptance/rejection threshold because there are two possible outcomes: (a) a bid over the reward $\xi_{j}$ that implies a rejection, and (b) a bid below the reward $\xi_{j}$ that implies an acceptance. It must be remembered that in a second-price auction, a carrier's reward is the second-best bid if the auction is won; the acceptance/rejection problem is equivalent to having a carrier that knows all competitors' bids and therefore knows in advance the secondlowest bid, which is $\xi_{j}$. Then, Equation (1)

$$
\begin{gathered}
b_{j}^{*} \in \arg \max E_{(\xi)}\left[\left(\xi-c\left(s_{j}\right)\right) I_{j}+\pi_{j+1}\left(s_{j+1} \mid z_{j}^{1}\right) I_{j}\right. \\
\left.+\pi_{j+1}\left(s_{j+1} \mid z_{j}^{0}\right)\left(1-I_{j}\right)\right] \\
b \in R, \quad I_{j}=1 \quad \text { if } \xi>b \text { and } I_{j}=0 \quad \text { if } \xi<b
\end{gathered}
$$

can be transformed into Equation (8), the acceptance/ rejection case:

$$
\begin{gathered}
b_{j}^{*} \in \arg \max \left[\left(\xi_{j}-c\left(s_{j}\right)+\pi_{j+1}\left(s_{j+1} \mid z_{j}^{1}\right)\right) I_{j},\right. \\
\left.\pi_{j+1}\left(s_{j+1} \mid z_{j}^{0}\right)\left(1-I_{j}\right)\right] \\
b \in R, \quad I_{j}=1 \quad \text { if } \xi_{j}>b \text { and } I_{j}=0 \text { if } \xi_{j}<b .
\end{gathered}
$$

If the bid submitted is $\xi_{j}>b$, future profits are $\xi_{j}-$ $c\left(s_{j}\right)+\pi_{j+1}\left(s_{j+1} \mid z_{j}^{1}\right)$; otherwise, if $\xi_{j}<b$, future profits are $\pi_{j+1}\left(s_{j+1} \mid z_{j}^{0}\right)$. Combining these profits, the acceptance rule is

$$
\xi_{j} \geq c\left(s_{j}\right)+\pi_{j+1}\left(s_{j} \mid z_{j}^{0}\right)-\pi_{j+1}\left(s_{j} \mid z_{j}^{1}\right) .
$$

Note that if there is a penalty for rejecting a contract denoted as $p_{j}$, then the acceptance rule becomes

$$
\xi_{j} \geq c\left(s_{j}\right)+\pi_{j+1}\left(s_{j+1} \mid z_{j}^{0}\right)-\pi_{j+1}\left(s_{j+1} \mid z_{j}^{1}\right)-p_{j} .
$$

A dynamic acceptance/rejection problem in lessthan-truckload (LTL) transportation is studied by Kleywegt and Papastavrou (1998), whose work deals with the distribution problem between LTL terminals where customers request a batch of loads between different origins and destinations. The dispatcher must dynamically accept or reject shipments and decide on truck origin or destination movements, number of trucks dispatched, and truck or loads assignments. The model considers a reward for served shipments, a constant penalty for rejected shipments, holding costs for vehicles and loads at terminals, and transportation costs between terminals. The problem is solved using a continuous-time Markov decision process. Conceptually, Kleywegt and Papastavrou's (1998) work is the closest to an acceptance/rejection VRPCE because 
request characteristics and rewards come from a known probability distribution and become known at the time of the request's arrival. However, the underlying problem is not a VRP, but a dynamic assignment-dispatching problem between a fixed set of origin-destination pairs. Equation (10) is equivalent to the optimal acceptance rule derived by Kleywegt and Papastavrou (1998) for the dynamic dispatching policies in an LTL problem.

\subsection{First-Price Auction Payments}

If the reward obtained for acquiring the right to serve a contract is the price submitted itself (reward $b_{j}$ if contract $s_{j}$ is won), the carrier pricing problem in the last contract $s_{N}$ is no longer in a situation strategically similar to a one-item second-price auction. The superscript " 1 " will be used to denote prices and expectations that only apply to the first-price auction payment format.

The bid that maximizes the bidder's expected profit for the last contract is

$$
\begin{aligned}
& b_{N}^{1^{*}} \in \arg \max E_{(\xi)}\left[\left(b-c\left(s_{N}\right)\right) I_{N}\right] \\
& b \in R, \quad I_{N}=1 \text { if } \xi>b \text { and } I_{N-1}=0 \text { if } \xi<b .
\end{aligned}
$$

The bid that maximizes the bidder's expected profit for contract $s_{N-1}$ is

$$
\begin{array}{r}
b_{N-1}^{1^{*}} \in \arg \max E_{(\xi)}\left[\left(b-c\left(s_{N-1}\right)\right) I_{N-1}+\pi_{N}\left(s_{N} \mid z_{N-1}^{1}\right) I_{N-1}\right. \\
+ \\
\left.+\pi_{N}\left(s_{N} \mid z_{N-1}^{0}\right)\left(1-I_{N-1}\right)\right] \\
b \in R, \quad I_{N-1}=1 \quad \text { if } \xi>b \text { and } I_{N-1}=0 \quad \text { if } \xi<b .
\end{array}
$$

The bid that maximizes the bidder's expected profit for contract $s_{j}$ is

$$
\begin{array}{r}
b_{N-1}^{1^{*}} \in \arg \max E_{(\xi)}\left[\left(b-c\left(s_{j}\right)\right) I_{j}+\pi_{N}\left(s_{j+1} \mid z_{j}^{1}\right) I_{N-1}\right. \\
\left.+\pi_{N}\left(s_{j+1} \mid z_{j}^{0}\right)\left(1-I_{j}\right)\right] \\
b \in R, \quad I_{j}=1 \text { if } \xi>b \text { and } I_{j}=0 \text { if } \xi<b .
\end{array}
$$

The future expected profits are calculated as follows:

$$
\begin{aligned}
& \pi_{j+1}^{1}\left(s_{j+1} \mid z_{j}^{I}\right) \\
& =E_{\left(\omega_{j+1}\right)}\left[E _ { ( \xi ) } \left[\left(b_{j+1}^{*}-c\left(s_{j+1}\right) \mid z_{j}^{I}\right) I_{j+1}+\pi_{j+2}^{1}\left(s_{j+2} \mid z_{j+1}^{1}\right) I_{j+1}\right.\right. \\
& \\
& \left.\left.\quad+\pi_{j+2}^{1}\left(s_{j+2} \mid z_{j+1}^{0}\right)\left(1-I_{j+1}\right)\right]\right] . \quad(12)
\end{aligned}
$$

Note that in general $\pi_{j+1}^{1}\left(s_{j+1} \mid z_{j}^{I}\right) \neq \pi_{j+1}\left(s_{j+1} \mid z_{j}^{I}\right)$. In auction terminology, this type of payment or reward corresponds to a first-price auction.

In general, the price that maximizes expected profits is (derivation in Appendix 2):

$$
b_{j}^{1^{*}} \in \arg \max \left[\int_{b}^{\infty}\left(b-c^{1 *}\left(s_{j}\right)\right) p(\xi) d(\xi)\right] \quad b \in R,
$$

where $c^{1 *}\left(s_{j}\right)=c\left(s_{j}\right)+\pi_{j+1}^{1}\left(s_{j+1} \mid z_{j}^{1}\right)-\pi_{j+1}^{1}\left(s_{j+1} \mid z_{j}^{0}\right)$.
Because the reward is no longer independent from the price submitted by the carrier, expression (13) is more involved than previously obtained expression (7). Furthermore, expression (13) indicates than the price submitted by the carrier is not necessarily the cost of servicing the arriving shipment $\left(c^{1^{*}}\left(s_{j}\right)\right)$. This type of pricing conceals the importance of repositioning costs and truck location/status as shown in Appendix 3; first-price auction payments may lead to ex ante inefficient outcomes. The same phenomenon was observed by Figliozzi, Mahmassani, and Jaillet (2005) when simulating first and second-price auction marketplaces. After employing first-price auction rules in the example previously studied in $\$ 4$, the prices submitted for contract $A B$ are: $b_{N}\left(s_{N}=A B\right)=$ $b_{N-1}\left(s_{N-1}=A B\right)$. This example clearly shows that prices with first-price auction payments do not necessarily reflect the cost of generating the transport service. For all of the abovementioned reasons, a second-price auction mechanism is employed to allocate contracts in a VRPCE.

\section{VRPCE Implementation}

The numerical implementation of a VRPCE strategy may be a difficult task for large fleets or a large number of contracts. Even assuming for the time being that $S_{j+1, \ldots, N}=\left\{s_{j+1}, \ldots, s_{N}\right\}$ is known at time $t_{j}$, each of the remaining $N-j$ contracts can be won or lost, generating a decision tree that has $2^{N-j}$ end nodes and corresponding possible future trajectories. Furthermore, one needs to consider solving an NP-hard problem (underlying VRPs) every time $c\left(s_{k}\right)$ has to be estimated.

A further source of difficulty is that the profitability of each path history up to a given time is dependent on the value of future costs (which are unknown when going forward). Conversely, the value of future costs are known when moving backward, however, one does not know the carrier's status at the time (a carrier's status is dependent on the previous path history). It is important to note that future fleet deployment depends on the present price tendered and its probability of winning. At the same time, the present price depends on the future profits and future fleet status.

The exact or computational estimation of Equation (7) may be quite involved or even intractable for small problems. In this section, we propose and evaluate a computationally straightforward approximation of Equation (7). This approach is denoted herein onestep-look-ahead (1SLA) because it limits the evaluation of the future profits to just one step or period into the future:

$$
\begin{aligned}
& \pi_{j+1}\left(s_{j+1} \mid z_{j}^{1}\right) \approx E_{\left(\omega_{j+1}\right)}\left[E_{(\xi)}\left[\left(\xi-c\left(s_{j+1}\right) \mid z_{j}^{1}\right) I_{j+1}\right]\right] \\
& \pi_{j+1}\left(s_{j+1} \mid z_{j}^{0}\right) \approx E_{\left(\omega_{j+1}\right)}\left[E_{(\xi)}\left[\left(\xi-c\left(s_{j+1}\right) \mid z_{j}^{0}\right) I_{j+1}\right]\right] .
\end{aligned}
$$


To estimate these two terms, it is assumed that the 1SLA carrier knows the true distribution of load arrivals over time and their spatial distribution $\Omega$, and also has an estimation of the endogenously generated prices or payments $\xi ; 30$ draws from $\Omega$ and $\xi$ are used to estimate these two terms. In this paper the 1SLA carrier approximates the price function as a normal function, whose mean and standard deviation are obtained from the whole sample of previous prices. The 1SLA approach uses this expression to estimate the price:

$$
\begin{aligned}
b\left(s_{j}\right)= & c\left(s_{j}\right)-E_{\left(\omega_{j+1}\right)}\left[E_{(\xi)}\left[\left(\xi-c\left(s_{j+1}\right) \mid z_{j}^{1}\right) I_{j+1}\right]\right] \\
& +E_{\left(\omega_{j+1}\right)}\left[E_{(\xi)}\left[\left(\xi-c\left(s_{j+1}\right) \mid z_{j}^{0}\right) I_{j+1}\right]\right] .
\end{aligned}
$$

The 1SLA carrier is compared against a static approach that does not take into account the stochastic nature of the problem. This is a natural benchmark because it represents a myopic carrier. This is herein denoted as the "static" approach, where the price submitted for a given shipment $s_{j}$ is simply $c\left(s_{j}\right)$. Simulations are used to simultaneously compare how the 1SLA and static approximations perform under different market settings (in our case limited to arrival rates and time windows). Market and simulation settings used to quantify and compare the performance of the two approaches are described next.

\subsection{Market and Simulation Settings}

The simulated market only enables the sale of truckload cargo capacity based mainly on price, yet still satisfies customer level of service demands (in this case, hard time windows or TW). The mixed-integer program formulation used to estimate $c\left(s_{j}\right)$ is based on the formulation proposed by Yang, Jaillet, and Mahmassani (2004). Shipments and vehicles are fully compatible in all cases; there are no special shipments or commodity-specific equipment. Three different TW length/shipment service duration ratios are simulated. These ratios are denoted short, medium, and long, a reference to the average time window length. The different time window lengths (TWL) for a shipment $s_{j}$, where $l d\left(s_{j}\right)$ denotes the function that returns the distance between a shipment origin and destination, are

- $\operatorname{TWL}\left(s_{j}\right)=1\left(l d\left(s_{j}\right)+0.25\right)+$ uniform $[0.0,1.0]$ (short)

- $\operatorname{TWL}\left(s_{j}\right)=2\left(l d\left(s_{j}\right)+0.25\right)+$ uniform $[0.0,2.0]$ (medium)

- $\operatorname{TWL}\left(s_{j}\right)=3\left(l d\left(s_{j}\right)+0.25\right)+$ uniform $[0.0,3.0]$ (long).

The shipments to be auctioned are circumscribed in a bounded geographical region. The simulated region is a 1 by 1 square area. Trucks travel from shipment origins to destinations at a constant unit speed (one unit distance per unit time). Shipment origins and destinations are uniformly distributed over the region. There is no explicit underlying network structure in the chosen origin-destination demand pattern. Alternatively, it can be seen as a network with an infinite number of origins and destinations (essentially each point in the set $[0,1] \times[0,1])$ that has an infinite number of corresponding links. Each and every link possesses an equal infinitesimal probability of occurrence. Vehicles are assumed to travel at a constant speed in a Euclidean two-dimensional space. Vehicles speeds are a unit; the average shipment length is $\cong 0.52$. Carriers' sole sources of revenue are the payments received when a shipment is acquired. Shippers' reservation prices are set as 1.41 units (diagonal of the square area) plus the loaded distance of the shipment. Carriers' costs are proportional to the total distance traveled by the fleet. It is assumed that all carriers have the same unit cost per mile.

The market is comprised of shippers that independently call for shipment procurement auctions, and two carriers. Each carrier operates two trucks. Different demand-supply ratios are studied. Arrivals in all cases follow Poisson processes, with arrival rates ranging from low to high. At a low arrival rate, all the shipments can be served (if some shipments are not serviced, it is due to a very short time window). At a high arrival rate carriers operate at capacity and many shipments have to be rejected. The expected interarrival time is normalized with respect to the market fleet size. The expected interarrival times are $1 / 2$ arrivals per unit time per truck, $2 / 2$ arrivals per unit time per truck, and 3/2 arrivals per unit time per truck (low, medium, and high arrival rates, respectively). The results obtained reflect the steady-state operation (1,000 arrivals and 10 iterations) of the simulated system.

Allocations follow the rules of a second-price reverse auction. It is important to highlight that carriers are competing for each shipment or contract. Carriers are simultaneously interacting in the same market, which better resembles the operation of a dynamic competitive market rather than the evaluation of each strategy separately (with no interaction) followed by a comparison of the separately obtained results. Simulation results that assess the quality of the 1SLA approximation in relation to the static approximation are presented next.

\subsection{Analysis of Results}

Tables 1 to 3 compare the results for the 1SLA carrier versus the static carrier. Table 1 illustrates that the 1SLA carrier outperforms its competitor profitwise, or obtains a higher market share when profit differences are not statistically significant.

Table 2 presents the average fleet utilization per carrier (fleet utilization reflects, on average, what percentage of the time trucks are not idle), which as 
Table 1 Profit and Number of Shipments Served Comparison

\begin{tabular}{|c|c|c|c|c|c|c|c|c|}
\hline $\begin{array}{l}\text { Arrival } \\
\text { rate }\end{array}$ & TW & $\begin{array}{c}\text { Carrier } \\
\text { type }\end{array}$ & $\begin{array}{c}\text { Average } \\
\text { profit }\end{array}$ & $\begin{array}{l}\text { St. dev. } \\
\text { profit }\end{array}$ & $\begin{array}{c}\text { Diff. } \\
\text { profit (\%) }\end{array}$ & $\begin{array}{l}\text { Average } \\
\text { served }\end{array}$ & $\begin{array}{l}\text { St. dev. } \\
\text { served }\end{array}$ & $\begin{array}{c}\text { Diff. } \\
\text { served (\%) }\end{array}$ \\
\hline \multirow[t]{5}{*}{ Low } & Short & $1 S L A$ & 103.44 & 1.81 & \multirow[t]{2}{*}{4.0} & 210.50 & 1.52 & \multirow[t]{2}{*}{-0.9} \\
\hline & & Static & 99.49 & 3.11 & & 212.50 & 2.22 & \\
\hline & Med. & $\begin{array}{l}\text { 1SLA } \\
\text { Static }\end{array}$ & $\begin{array}{l}63.85 \\
46.59\end{array}$ & $\begin{array}{l}1.62 \\
1.43\end{array}$ & 37.0 & $\begin{array}{l}288.30 \\
210.90\end{array}$ & $\begin{array}{l}3.64 \\
3.63\end{array}$ & 36.7 \\
\hline & Long & $1 S L A$ & 63.44 & 1.96 & \multirow[t]{2}{*}{79.8} & 306.70 & 4.28 & \multirow[t]{2}{*}{58.7} \\
\hline & & Static & 35.29 & 0.99 & & 193.30 & 4.28 & \\
\hline \multirow[t]{6}{*}{ Med. } & Short & $1 S L A$ & 242.59 & 3.19 & \multirow[t]{2}{*}{12.5} & 366.80 & 3.92 & \multirow[t]{2}{*}{-7.0} \\
\hline & & Static & 215.60 & 3.52 & & 394.40 & 2.55 & \\
\hline & Med. & $1 S L A$ & 162.57 & 3.84 & \multirow[t]{2}{*}{-0.5} & 515.60 & 2.37 & \multirow[t]{2}{*}{12.2} \\
\hline & & Static & 163.32 & 3.35 & & 459.60 & 2.57 & \\
\hline & Long & 1 SLA & 144.32 & 3.09 & \multirow[t]{2}{*}{19.8} & 576.20 & 4.35 & \multirow[t]{2}{*}{36.9} \\
\hline & & Static & 120.49 & 2.53 & & 420.80 & 4.79 & \\
\hline \multirow[t]{6}{*}{ High } & Short & $1 S L A$ & 387.59 & 4.63 & \multirow[t]{2}{*}{16.9} & 475.50 & 5.27 & \multirow[t]{2}{*}{-7.4} \\
\hline & & Static & 331.58 & 3.99 & & 513.30 & 2.52 & \\
\hline & Med. & $1 S L A$ & 337.55 & 5.56 & \multirow[t]{2}{*}{10.1} & 605.40 & 5.12 & \multirow[t]{2}{*}{1.1} \\
\hline & & Static & 306.70 & 3.00 & & 598.80 & 4.47 & \\
\hline & Long & 1SLA & 315.04 & 6.07 & \multirow[t]{2}{*}{0.1} & 651.30 & 7.40 & \multirow[t]{2}{*}{2.5} \\
\hline & & Static & 314.80 & 4.09 & & 635.40 & 5.74 & \\
\hline
\end{tabular}

expected increases when the number of shipments served (Table 1) or arrival rate increases. The average loaded distance per carrier shows a distinct pattern; the 1SLA carrier tends to serve shorter shipments when there is a short time window. This is an intuitive result, because shorter shipments tend to utilize fewer resources. The difference in profits and number of shipments handled decreases percentagewise when the arrival rate is high and the time windows are not short. This can be explained by the fact that the 1SLA carrier is operating at capacity. When supply is tight all carriers tend to do well.
Table 3 shows how the 1SLA carrier modifies the static service cost per arriving shipment. The static insertion cost is equal to $c\left(s_{j}\right)$ minus shipment $s_{j}$ loaded distance (loaded distance associated costs are equal for all carriers). With shorter time windows prices are increased to reflect that it is harder to serve additional shipments when time windows are tight; the static approach tends to undervalue the "true" cost of serving shipments when time windows are short. For larger time windows (low and medium arrival rates) prices are decreased; the static approach tends to overvalue the true cost of serving shipments when

Table 2 Fleet Utilization and Average Loaded Distance per Shipment Served Comparison

\begin{tabular}{|c|c|c|c|c|c|c|c|c|}
\hline $\begin{array}{l}\text { Arrival } \\
\text { rate }\end{array}$ & TW & $\begin{array}{l}\text { Carrier } \\
\text { type }\end{array}$ & $\begin{array}{c}\text { Fleet } \\
\text { utilizat. }(\%)\end{array}$ & $\begin{array}{c}\text { St. dev. } \\
\text { fleet utilizat. }\end{array}$ & $\begin{array}{c}\text { Diff. } \\
\text { utilizat. (\%) }\end{array}$ & $\begin{array}{l}\text { Average } \\
\text { loaded dist. }\end{array}$ & $\begin{array}{l}\text { St. dev. } \\
\text { loaded dist. }\end{array}$ & $\begin{array}{c}\text { Diff. loaded } \\
\text { dist. (\%) }\end{array}$ \\
\hline \multirow[t]{4}{*}{ Low } & Short & $1 S L A$ & 32.60 & 0.0013 & -4.0 & 0.5083 & 0.0045 & -4.9 \\
\hline & & Static & 33.97 & 0.0027 & & 0.5343 & 0.0079 & \\
\hline & Med. & 1SLA & $\begin{array}{l}47.07 \\
32.98\end{array}$ & 0.0040 & 42.7 & $\begin{array}{l}0.5265 \\
0.5230\end{array}$ & 0.0049 & 0.7 \\
\hline & Long & $\begin{array}{l}\text { 1SLA } \\
\text { Static }\end{array}$ & $\begin{array}{l}48.85 \\
29.80\end{array}$ & $\begin{array}{l}0.0034 \\
0.0031\end{array}$ & 63.9 & $\begin{array}{l}0.5261 \\
0.5219\end{array}$ & $\begin{array}{l}0.0050 \\
0.0056\end{array}$ & 0.8 \\
\hline \multirow[t]{3}{*}{ Med. } & Short & $\begin{array}{l}1 S L A \\
\text { Static }\end{array}$ & $\begin{array}{l}57.68 \\
62.06\end{array}$ & $\begin{array}{l}0.0019 \\
0.0035\end{array}$ & -7.1 & $\begin{array}{l}0.5089 \\
0.5263\end{array}$ & $\begin{array}{l}0.0073 \\
0.0050\end{array}$ & -3.3 \\
\hline & Med. & $\begin{array}{l}\text { 1SLA } \\
\text { Static }\end{array}$ & $\begin{array}{l}80.71 \\
71.58\end{array}$ & $\begin{array}{l}0.0036 \\
0.0042\end{array}$ & 12.8 & $\begin{array}{l}0.5237 \\
0.5274\end{array}$ & $\begin{array}{l}0.0077 \\
0.0041\end{array}$ & -0.7 \\
\hline & Long & $\begin{array}{l}\text { 1SLA } \\
\text { Static }\end{array}$ & $\begin{array}{l}86.99 \\
61.62\end{array}$ & $\begin{array}{l}0.0049 \\
0.0057\end{array}$ & 41.2 & $\begin{array}{l}0.5246 \\
0.5244\end{array}$ & $\begin{array}{l}0.0068 \\
0.0063\end{array}$ & 0.0 \\
\hline \multirow[t]{3}{*}{ High } & Short & $\begin{array}{l}\text { 1SLA } \\
\text { Static }\end{array}$ & $\begin{array}{l}74.38 \\
80.96\end{array}$ & $\begin{array}{l}0.0026 \\
0.0029\end{array}$ & -8.1 & $\begin{array}{l}0.5087 \\
0.5326\end{array}$ & $\begin{array}{l}0.0097 \\
0.0060\end{array}$ & -4.5 \\
\hline & Med. & $\begin{array}{l}\text { 1SLA } \\
\text { Static }\end{array}$ & $\begin{array}{l}95.43 \\
93.83\end{array}$ & $\begin{array}{l}0.0009 \\
0.0024\end{array}$ & 1.7 & $\begin{array}{l}0.5250 \\
0.5285\end{array}$ & $\begin{array}{l}0.0050 \\
0.0066\end{array}$ & -0.7 \\
\hline & Long & $\begin{array}{l}1 S L A \\
\text { Static }\end{array}$ & $\begin{array}{l}97.21 \\
92.64\end{array}$ & $\begin{array}{l}0.0013 \\
0.0031\end{array}$ & 4.9 & $\begin{array}{l}0.5269 \\
0.5244\end{array}$ & $\begin{array}{l}0.0064 \\
0.0048\end{array}$ & 0.5 \\
\hline
\end{tabular}


Table 3 Average Insertion Costs and Future Profits Comparison

\begin{tabular}{lcccccrr}
\hline \multirow{2}{*}{ Arrival rate } & TW & $\begin{array}{c}\text { Carrier } \\
\text { type }\end{array}$ & $\begin{array}{c}\text { Average static } \\
\text { insertion cost }\end{array}$ & $\begin{array}{c}\text { Average } \\
\pi_{j+1}\left(s_{j+1} \mid z_{j}^{1}\right) \\
(1)\end{array}$ & $\begin{array}{c}\text { Average } \\
\pi_{j+1}\left(s_{j+1} \mid z_{j}^{0}\right) \\
(2)\end{array}$ & $\begin{array}{r}\text { Diff. } \\
(2)-(1)\end{array}$ & $\begin{array}{r}\text { (2) }-(1) \\
\text { insertion } \\
\text { cost (\%) }\end{array}$ \\
\hline Low & Short & 1SLA & 0.369 & 0.338 & 0.355 & 0.017 & 4.74 \\
& Med. & 1SLA & 0.405 & 0.181 & 0.143 & -0.038 & -9.39 \\
& Long & 1SLA & 0.386 & 0.194 & 0.144 & -0.050 & -12.83 \\
\multirow{4}{*}{ Med. } & Short & 1SLA & 0.378 & 0.375 & 0.451 & 0.076 & 20.15 \\
& Med. & 1SLA & 0.397 & 0.219 & 0.197 & -0.022 & -5.52 \\
& Long & 1SLA & 0.353 & 0.188 & 0.161 & -0.027 & -7.78 \\
High & Short & 1SLA & 0.369 & 0.376 & 0.515 & 0.139 & 37.62 \\
& Med. & 1SLA & 0.391 & 0.332 & 0.353 & 0.021 & 5.32 \\
& Long & 1SLA & 0.348 & 0.260 & 0.271 & 0.011 & 3.28 \\
\hline
\end{tabular}

time windows are short. However, if the fleet utilization is too high (over $90 \%$ as shown in Table 2), the static approach tends to undervalue the true cost of serving shipments even when time windows are long.

There are two distinct forces operating on the market prices: time window lengths and arrival rates. The 1SLA strategy manages to outperform the static pricing approach either profitwise or with higher market shares when profits are not significantly different. In addition, the 1SLA strategy seems able to price discriminately by shipment characteristics (e.g., by the shipment loaded distance). As expected, taking the future into account outperforms the myopic approach. The same type of results has been found in the work of Powell, Towns, and Marar (2000); however, it is important to notice that our work deals with pricing decisions, whereas Powell's deals with routing or assignment decisions.

\section{Informational and Behavioral Assumptions in the VRPCE Problem}

The formulation presented in $\S 3$ is general enough to readily accommodate variants to the VRPCE, whereas the solution procedures of $\S \S$ three and four still apply. In a real-life application, the arrival rates of contracts $(\Omega)$ and price distributions $(\xi)$ need to be estimated. In such cases, when carriers must work with the estimated distributions, $\left(\widehat{\Omega}=f\left(y_{0}, y_{1}, \ldots\right.\right.$, $\left.\left.y_{j-1}\right)\right)$ and $\left(\hat{\xi}=g\left(y_{0}, y_{1}, \ldots, y_{j-1}\right)\right)$, the amount of information revealed can have a high impact on the quality of the estimated distributions. Following the classification used by Figliozzi, Mahmassani, and Jaillet (2003b), the two extremes of the information spectrum can be denoted as: (a) a maximum information environment (MaIE) where all arrivals and prices are revealed or (b) a minimum information environment (MiIE) where acceptance or rejection is the only information provided. These two extreme scenarios approximate two realistic situations. Maximum information would correspond to a totally transparent Internet auction where all arrival/auction information is accessed by participants. Minimum information would correspond to a shipper selectively telephoning carriers for a quote, with the shipper only calling back the carrier that was selected.

Some key assumptions are made in the VRPCE in order to keep the problem not only relevant from the economic and routing point of view, but also tractable and conceptually well defined. The assumed price clearance rules (similar to second-price auctions) and independence (the independence assumption herein) between carrier actions and prices (or contract arrivals) assures that a rational carrier (with adequate computational capabilities) will only price his services at the incremental cost provided by Equation (7). This fact is relevant because it takes away any strategic element from the VRPCE and focuses the attention on efficient routing and costing. Computational results have also shown that the second price with information about market-clearing prices generates more wealth than first-price auction clearing rules or second-price auctions with minimum information (MiIE) (Figliozzi, Mahmassani, and Jaillet 2005).

However, the "independence assumption" is a strong assumption, especially in the full-information case (MaIE). With full-information numerous data can be collected by the carriers and there may exist an incentive to use the revealed data to model how competitors price contracts. If this takes place, a carrier may model competitors' behavior and add causal links between a carrier's actions and future prices (Figliozzi 2004). The independence assumption is more suitable when there is a large number of competitors, no participation fees or rejection penalties, information about market-clearing prices, and unconstrained capacity as the game-theoretical auction and industrial organization literature indicates (Krishna 2002, Tirole 1989). Therefore, the independence assumption is more suitable in a truly competitive environment, hence the "CE" in VRPCE. 


\section{Conclusion}

This paper presents the VRPCE, illustrated as a dynamic extension of the traveling-salesmen problem with profits. In the VRPCE a carrier that attempts to act rationally must estimate the incremental cost of servicing the new service requests as they arrive dynamically. An intuitive optimal price expression for the VRPCE problem reveals that full incremental costs include: (a) the expected change due to altering the current fleet assignment scheme, and (b) the opportunity costs on future profits created by serving a new contract. A simple example showed that carriers' prices under first-price auction payment rules do not necessarily reflect the cost of servicing transportation requests.

The proposed VRPCE problem provides an adequate framework with which to evaluate the impact of new service arrivals or changes in the fleet/ shipments status in a competitive environment. Competition may involve either (a) two or more competing (opposing) options such as accept or reject, use private fleet or use common carrier, charge price A or charge price $\mathrm{B}$, etc. or $(\mathrm{b})$ a price competition with a rival company. Pricing is explicitly incorporated into the formulation; this is achieved by relaxing a sequential auctions mechanism to model a competitive environment that makes explicit the carriers' behavioral assumptions in the VRPCE problem. A simulationbased approach to evaluate service costs was proposed and evaluated; the proposed approach not only outperforms a static pricing, but it also intuitively price discriminates by market arrival rate, time windows, and shipment characteristics.

\section{Acknowledgments}

The authors thank three anonymous referees and the associate editor for helpful comments. This work is based in part on funding from the National Science Foundation through Grants CMS 0231517 and DMI 0230981 to the University of Maryland and the Massachusetts Institute of Technology, respectively. All results and opinions are those of the authors.

\section{Appendix 1}

If the value $p(b=\xi)$ is not negligible, and for a given constant $k$, such that $0 \leq k \leq 1$, let $k p(b=\xi)$ represent the probability of acquiring the contract when there is a price tie. For a $\varepsilon>0$ arbitrarily small, the expected value of the present plus future profits for any bid $b \in R$ can be expressed as

$$
\begin{aligned}
E_{(\xi)} & {\left[\left(\xi-c\left(s_{j}\right)\right) I_{j}+\pi_{j+1}\left(s_{j+1} \mid z_{j}^{1}\right) I_{j}+\pi_{j+1}\left(s_{j+1} \mid z_{j}^{0}\right)\left(1-I_{j}\right)\right] } \\
= & \int_{b+\varepsilon}^{\infty}\left(\xi-c\left(s_{j}\right)\right) p(\xi) d(\xi)+\int_{b+\varepsilon}^{\infty} \pi_{j+1}\left(s_{j+1} \mid z_{j}^{1}\right) p(\xi) d(\xi) \\
& +\int_{-\infty}^{b-\varepsilon} \pi_{j+1}\left(s_{j+1} \mid z_{j}^{0}\right) p(\xi) d(\xi)+k p(\xi=b) *\left(b-c\left(s_{j}\right)\right) \\
& +k p(\xi=b) *\left(\pi_{j+1}\left(s_{j+1} \mid z_{j}^{1}\right)+\pi_{j+1}\left(s_{j+1} \mid z_{j}^{0}\right)\right) .
\end{aligned}
$$

The first two integrals are evaluated in the interval $[b+\varepsilon, \infty]$ because they equal zero as long as price $b$ is greater than the competitors' prices $(b>\xi)$, or equivalently, if the contract $s_{j}$ is won. The last integral is evaluated in the interval $[-\infty, b-\varepsilon]$ because it is not zero only when the bid $b$ is bigger than the competitors' bids $(b>\xi)$, or equivalently, if the contract $s_{j}$ is lost. Grouping terms in (A1):

$$
\begin{aligned}
& \int_{b+\varepsilon}^{\infty}\left(\xi-c\left(s_{j}\right)+\pi_{j+1}\left(s_{j+1} \mid z_{j}^{1}\right)-\pi_{j+1}\left(s_{j+1} \mid z_{j}^{0}\right)\right) p(\xi) d(\xi) \\
& \quad+k p(\xi=b) *\left(b-c\left(s_{j}\right)\right)+\int_{-\infty}^{\infty} \pi_{j+1}\left(s_{j+1} \mid z_{j}^{0}\right) p(\xi) d(\xi) \\
& \quad+k p(\xi=b) *\left(\pi_{j+1}\left(s_{j+1} \mid z_{j}^{1}\right)\right)-k p(\xi=b) *\left(\pi_{j+1}\left(s_{j+1} \mid z_{j}^{0}\right)\right) .
\end{aligned}
$$

Regrouping once more:

$$
\begin{aligned}
\int_{b+\varepsilon}^{\infty} & \left(\xi-c\left(s_{j}\right)+\pi_{j+1}\left(s_{j+1} \mid z_{j}^{1}\right)-\pi_{j+1}\left(s_{j+1} \mid z_{j}^{0}\right)\right) p(\xi) d(\xi) \\
& +k p(\xi=b) *\left[\xi-c\left(s_{j}\right)+\pi_{j+1}\left(s_{j+1} \mid z_{j}^{1}\right)-\pi_{j+1}\left(s_{j+1} \mid z_{j}^{0}\right)\right] \\
& +\pi_{j+1}\left(s_{j+1} \mid z_{j}^{0}\right) .
\end{aligned}
$$

Again, the term $-c\left(s_{j}\right)+\pi_{j+1}\left(s_{j+1} \mid z_{j}^{1}\right)-\pi_{j+1}\left(s_{j+1} \mid z_{j}^{0}\right)$ does not depend on the realization of $\xi$ or the value of $b$. Denoting $c_{j}^{*}=c\left(s_{j}\right)-\pi_{j+1}\left(s_{j+1} \mid z_{j}^{1}\right)+\pi_{j+1}\left(s_{j+1} \mid z_{j}^{0}\right)$ and replacing in (A2):

$$
\begin{aligned}
\int_{b+\varepsilon}^{\infty} & \left(\xi-c_{j}^{*}\left(s_{j}\right)\right) p(\xi) d(\xi) \\
& +k p(\xi=b) *\left[\xi-c_{j}^{*}\left(s_{j}\right)\right]+\pi_{j+1}\left(s_{j+1} \mid z_{j}^{0}\right) .
\end{aligned}
$$

Equation (A3) is strategically equivalent to a second-price auction, where $\xi$ represents the distribution of the best competitors' prices and $c_{j}^{*}$ is the carrier's cost. The price that maximizes Equation (A3) is simply $c_{j}^{*}$; the proof that $c_{j}^{*}$ is optimal parallels the proof for the one-item second-price auction. The term $\pi_{j+1}\left(s_{j+1} \mid z_{j}^{0}\right)$ is constant and may be taken out without altering the comparisons.

Assuming $b>c_{j}^{*}$, then

$$
\begin{aligned}
\int_{b+\varepsilon}^{\infty}(\xi & \left.-c_{j}^{*}\right) p(\xi) d(\xi)+k p(\xi=b) *\left[\xi-c_{j}^{*}\left(s_{j}\right)\right] \\
\leq & \int_{b+\varepsilon}^{\infty}\left(\xi-c_{j}^{*}\right) p(\xi) d(\xi)+p(\xi=b)\left[\xi-c_{j}^{*}\left(s_{j}\right)\right] \\
& +\int_{c_{j}^{*}}^{b-\varepsilon}\left(\xi-c_{j}^{*}\right) p(\xi) d(\xi)
\end{aligned}
$$

because all the elements in the last integral are equal to or larger than zero, and $p(\xi=b) \geq k p(\xi=b)$ is also larger than zero.

Assuming $b<c_{j}^{*}$, then

$$
\begin{aligned}
\int_{c_{j}^{*}}^{\infty}\left(\xi-c_{j}^{*}\right) p(\xi) d(\xi) \\
\quad \geq \int_{c_{j}^{*}}^{\infty}\left(\xi-c_{j}^{*}\right) p(\xi) d(\xi)+\int_{b+\varepsilon}^{c_{j}^{*}}\left(\xi-c_{j}^{*}\right) p(\xi) d(\xi) \\
\quad+k p(\xi=b) *\left[\xi-c_{j}^{*}\left(s_{j}\right)\right]
\end{aligned}
$$

because in the last integral the term $\xi-c_{j}^{*}$ is negative and in the last term $k p(\xi=b) *\left[b-c_{j}^{*}\left(s_{j}\right)\right]$ is negative. Therefore, 
Equation (A3) is maximized when $b=c_{j}^{*}$. Therefore, the optimal bid for a shipment $s_{j}$ is equal to (7): $c_{j}^{*}=\bar{c}\left(s_{j}\right)-$ $\pi_{j+1}\left(s_{j} \mid z_{j}^{1}\right)+\pi_{j+1}\left(s_{j} \mid z_{j}^{0}\right)$

\section{Appendix 2}

For the first-price auction payment, the optimal price must maximize expected profits. The expected value of the present plus future profits for any bid $b \in R$ can be expressed as

$$
\begin{aligned}
E_{(\xi)}\left[\left(b-c\left(s_{j}\right)\right) I_{j}+\pi_{j+1}^{1}\left(s_{j+1} \mid z_{j}^{1}\right) I_{j}+\pi_{j+1}^{1}\left(s_{j+1} \mid z_{j}^{0}\right)\left(1-I_{j}\right)\right] \\
=\int_{b}^{\infty}\left(b-c\left(s_{j}\right)\right) p(\xi) d(\xi)+\int_{b}^{\infty} \pi_{j+1}^{1}\left(s_{j+1} \mid z_{j}^{1}\right) p(\xi) d(\xi) \\
\quad+\int_{-\infty}^{b} \pi_{j+1}^{1}\left(s_{j+1} \mid z_{j}^{0}\right) p(\xi) d(\xi) .
\end{aligned}
$$

The first two integrals are evaluated in the interval $[b, \infty]$ because they equal zero as long as price $b$ is greater than the competitors' prices $(b>\xi)$, or equivalently, if the contract $s_{j}$ is won. The last integral is evaluated in the interval $[-\infty, b]$ because it is not zero only when the bid $b$ is bigger than the competitors' bids $(b>\xi)$, or equivalently, if the contract $s_{j}$ is lost. Grouping terms:

$$
\begin{aligned}
\int_{b}^{\infty} & \left(b-c\left(s_{j}\right)+\pi_{j+1}^{1}\left(s_{j+1} \mid z_{j}^{1}\right)-\pi_{j+1}^{1}\left(s_{j+1} \mid z_{j}^{0}\right)\right) p(\xi) d(\xi) \\
& +\int_{-\infty}^{\infty} \pi_{j+1}^{1}\left(s_{j+1} \mid z_{j}^{0}\right) p(\xi) d(\xi) \\
= & \int_{b}^{\infty}\left(b-c\left(s_{j}\right)+\pi_{j+1}^{1}\left(s_{j+1} \mid z_{j}^{1}\right)-\pi_{j+1}^{1}\left(s_{j+1} \mid z_{j}^{0}\right)\right) p(\xi) d(\xi) \\
\quad & +\pi_{j+1}^{1}\left(s_{j+1} \mid z_{j}^{0}\right) .
\end{aligned}
$$

The last term is a constant. Replacing $c^{1^{*}}\left(s_{j}\right)=c\left(s_{j}\right)+$ $\pi_{j+1}^{1}\left(s_{j+1} \mid z_{j}^{1}\right)-\pi_{j+1}^{1}\left(s_{j+1} \mid z_{j}^{0}\right)$, the optimal bid maximizes:

$$
b_{j}^{1^{*}} \in \arg \max \left[\int_{b}^{\infty}\left(b-c^{1^{*}}\left(s_{j}\right)\right) p(\xi) d(\xi)\right] \quad b \in \mathrm{R} .
$$

There is no general expression for the optimal bid that is "distribution free" and equivalent to expression (7). For each particular distribution of prices there will be a corresponding optimal price function. For example, if prices are uniformly distributed in the interval $[0, u]$, the optimal price is

$$
b_{j}^{1 *}=\frac{u+c^{1 *}\left(s_{j}\right)}{2} \quad \text { for } 0 \leq c^{1 *}\left(s_{j}\right) \leq u ;
$$

in particular, $b_{j}^{1 *}=u / 2$ for $c^{1 *}\left(s_{j}\right)=0$ and $b_{j}^{1 *}>u$ for $c^{1 *}\left(s_{j}\right)>u$.

\section{Appendix 3}

This appendix applies first-price auction payment mechanisms to the example presented in \$5. To illustrate the concepts and formulas, let us initially assume that the truck is originally located at vertex $A$. If contract $A B$ has arrived at time $t_{N}$ and the carrier status is $z_{N}=\{A\}$ (truck is empty and idle).

Best responses are calculated using

$$
b_{j}^{1^{*}} \in \arg \max \left[\int_{b}^{\infty}\left(b-c^{1 *}\left(s_{j}\right)\right) p(\xi) d(\xi)\right] \quad b \in \mathrm{R} .
$$

When the last shipment arrives, for each cost there is a price that maximizes expected profits:

$$
\begin{aligned}
& c_{N}=3 \\
& \pi^{1 *}\left(c_{N}=3, b_{N}=3\right)=0, \\
& c_{N}=2 \\
& \pi^{1 *}\left(c_{N}=2, b_{N}=3-\varepsilon\right)=(3-\varepsilon-2) *(1 / 4) \approx 1 / 4 \\
& \pi^{1 *}\left(c_{N}=2, b_{N}=2-\varepsilon\right)=(2-\varepsilon-2) *(1 / 4) \\
& +(2-\varepsilon-2) *(1 / 2) \approx 0, \\
& c_{N}=1 \\
& \pi^{1 *}\left(c_{N}=1, b_{N}=3-\varepsilon\right)=(3-\varepsilon-1) *(1 / 4) \approx 1 / 2 \\
& \pi^{1 *}\left(c_{N}=1, b_{N}=2-\varepsilon\right)=(2-\varepsilon-1) *(1 / 4) \\
& +(2-\varepsilon-1) *(1 / 2) \approx 3 / 4, \\
& c_{N}=0 \\
& \pi^{1 *}\left(c_{N}=0, b_{N}=3-\varepsilon\right)=(3-\varepsilon-0) *(1 / 4) \approx 3 / 4 \\
& \pi^{1 *}\left(c_{N}=0, b_{N}=2-\varepsilon\right)=(2-\varepsilon-0) *(1 / 4) \\
& +(2-\varepsilon-0) *(1 / 2) \approx 3 / 2 \\
& \pi^{1 *}\left(c_{N}=0, b_{N}=1-\varepsilon\right)=(1-\varepsilon-0) *(1 / 4)+(1-\varepsilon-0) *(1 / 2) \\
& +(1-\varepsilon-0) *(1 / 4) \approx 1 \text {. }
\end{aligned}
$$

Then the prices for the last shipment are simply the best responses:

$$
\begin{gathered}
b_{N}\left(s_{N}=A B, c\left(s_{N}\right)=1\right)=2-\varepsilon \\
b_{N}\left(s_{N}=D A, c\left(s_{N}\right)=2\right)=3-\varepsilon .
\end{gathered}
$$

Let us now assume that the truck is located at vertex $A$ and idle at time $t_{N-1}$, with corresponding $z_{N-1}=\{A\}$. If contract $A B$ has arrived at time $t_{N-1}$ and the carrier status is $z_{N-1}=$ $\{A\}$ (truck is empty and idle), the incremental cost in this case is

$$
c\left(s_{N-1}=A B\right)=\mathrm{d}\left(\mathrm{a}, z_{N-1}^{1}, t_{N-1}^{\prime}\right)-\mathrm{d}\left(\mathrm{a}, z_{N-1}^{0}, t_{N-1}^{\prime}\right)=1-0=1 .
$$

The term $\pi_{N}^{1}\left(s_{N} \mid z_{N-1}^{1}\right)$ is calculated by taking into account that $z_{N-1}^{1}=\{A ; A B\}$ and that the future status is going to be $z_{N}=\{B\}$; then $\mathrm{c}\left(s_{N}=A B\right)=2$ and $\mathrm{c}\left(s_{N}=D A\right)=3$. For the former cost the expected profit is

$$
E_{(\xi)}\left[\left(b_{N}^{1 *}-c\left(s_{N}=A B\right)\right) I_{N}\right]=1 / 4 .
$$

For the latter cost the expected profit is

$$
E_{(\xi)}\left[\left(b_{N}^{1 *}-c\left(s_{N}=D A\right)\right) I_{N}\right]=0 .
$$

The term $\pi_{N}^{1}\left(s_{N} \mid z_{N-1}^{1}\right)$ is then estimated as

$$
\begin{aligned}
\pi_{N}^{1}\left(s_{N} \mid z_{N-1}^{1}\right) & =E_{\left(\omega_{N}\right)}\left[E_{(\xi)}\left[\left(b_{N}^{1 *}-\mathrm{c}\left(s_{N}\right) \mid z_{N-1}^{1}\right) I_{N}\right]\right] \\
& =(1 / 2)(1 / 4)+(1 / 2) 0=1 / 8 .
\end{aligned}
$$

The term $\pi_{N}^{1}\left(s_{N} \mid z_{N-1}^{0}\right)$ is calculated by taking into account that $z_{N-1}^{0}=\{A\}$ and the future status is going to be $z_{N}=\{A\}$; then, $\mathrm{c}\left(s_{N}=A B\right)=1$ and $\mathrm{c}\left(s_{N}=D A\right)=2$. For the former cost the expected profit is

$$
E_{(\xi)}\left[\left(b_{N}^{1 *}-c\left(s_{N}=A B\right)\right) I_{N}\right]=3 / 4 .
$$


For the latter cost the expected profit is

$$
E_{(\xi)}\left[\left(b_{N}^{1 *}-\mathrm{c}\left(s_{N}=D A\right)\right) I_{N}\right]=1 / 4 .
$$

The term $\pi_{N}^{1}\left(s_{N} \mid z_{N-1}^{0}\right)$ is then estimated as

$$
\begin{aligned}
\pi_{N}^{1}\left(s_{N} \mid z_{N-1}^{1}\right) & =E_{\left(\omega_{N}\right)}\left[E_{(\xi)}\left[\left(b_{N}^{1 *}-\mathrm{c}\left(s_{N}\right) \mid z_{N-1}^{0}\right) I_{N}\right]\right] \\
& =(1 / 2)(3 / 4)+(1 / 2)(1 / 4)=1 / 2
\end{aligned}
$$

Then, the cost $c^{1 *}\left(s_{N-1}\right)$ is

$$
c^{1 *}\left(s_{N-1}=A B\right)=1-1 / 8+1 / 2=11 / 8 .
$$

The best response to this cost is a price:

$$
b_{N-1}\left(s_{N-1}=A B\right)=2-\varepsilon .
$$

Let us now assume that the truck is located at vertex $A$ and is idle at time $t_{N-1}$ with corresponding $z_{N-1}=\{A\}$. If contract $D A$ has arrived at time $t_{N-1}$, the carrier status is $z_{N-1}=\{A\}$ (truck is empty and idle) and the incremental cost is in this case is

$$
\begin{aligned}
c\left(s_{N-1}=D A\right) & =\mathrm{d}\left(\mathrm{a}, z_{N-1}^{1}, t_{N-1}^{\prime}\right)-\mathrm{d}\left(\mathrm{a}, z_{N-1}^{0}, t_{N-1}^{\prime}\right) \\
& =2-0=2 .
\end{aligned}
$$

The term $\pi_{N}^{1}\left(s_{N} \mid z_{N-1}^{1}\right)$ is calculated by taking into account that $z_{N-1}^{1}=\{A ; D A\}$ and the future status is going to be $z_{N}=\{D, D A\}$; then, $\mathrm{c}\left(s_{N}=A B\right)=1$ and $\mathrm{c}\left(s_{N}=D A\right)=0$. For the former cost the expected profit is

$$
E_{(\xi)}\left[\left(b_{N}^{1 *}-c\left(s_{N}=A B\right)\right) I_{N}\right]=3 / 4 .
$$

For the latter cost the expected profit is

$$
E_{(\xi)}\left[\left(b_{N}^{1 *}-\mathrm{c}\left(s_{N}=D A\right)\right) I_{N}\right]=3 / 2 .
$$

The term $\pi_{N}^{1}\left(s_{N} \mid z_{N-1}^{1}\right)$ is then estimated as

$$
\begin{aligned}
\pi_{N}^{1}\left(s_{N} \mid z_{N-1}^{1}\right) & =E_{\left(\omega_{N}\right)}\left[E_{(\xi)}\left[\left(b_{N}^{1 *}-\mathrm{c}\left(s_{N}\right) \mid z_{N-1}^{1}\right) I_{N}\right]\right] \\
& =(1 / 2)(3 / 4)+(1 / 2)(3 / 2)=9 / 8 .
\end{aligned}
$$

The term $\pi_{N}^{1}\left(s_{N} \mid z_{N-1}^{0}\right)$ is calculated by taking into account that $z_{N-1}^{0}=\{A\}$ and the future status is going to be $z_{N}=\{A\}$; then, $\mathrm{c}\left(s_{N}=A B\right)=1$ and $\mathrm{c}\left(s_{N}=D A\right)=2$. For the former cost the expected profit is

$$
E_{(\xi)}\left[\left(b_{N}^{1 *}-c\left(s_{N}=A B\right)\right) I_{N}\right]=3 / 4 .
$$

For the latter cost the expected profit is

$$
E_{(\xi)}\left[\left(b_{N}^{1 *}-\mathrm{c}\left(s_{N}=D A\right)\right) I_{N}\right]=1 / 4 .
$$

The term $\pi_{N}\left(s_{N} \mid z_{N-1}^{0}\right)$ is then estimated as

$$
\begin{aligned}
\pi_{N}^{1}\left(s_{N} \mid z_{N-1}^{1}\right) & =E_{\left(\omega_{N}\right)}\left[E_{(\xi)}\left[\left(b_{N}^{1 *}-\mathrm{c}\left(s_{N}\right) \mid z_{N-1}^{0}\right) I_{N}\right]\right] \\
& =(1 / 2)(3 / 4)+(1 / 2)(1 / 4)=1 / 2 .
\end{aligned}
$$

Then, the cost $c^{1 *}\left(s_{N-1}\right)$ is

$$
c^{1 *}\left(s_{N-1}=D A\right)=2-9 / 8+1 / 2=11 / 8 .
$$

The best response to this cost is a price

$$
b_{N-1}\left(s_{N-1}=D A\right)=2-\varepsilon .
$$

The profits are

$(2-11 / 8) *(1 / 4)+(2-11 / 8) *(1 / 2)=5 / 32+10 / 32=15 / 32$.

With a price of $3-\varepsilon$, profits are smaller

$$
(3-11 / 8) *(1 / 4)=13 / 32 \text {. }
$$

This simple example illustrates the importance of the given or assumed price distribution when payments are similar to first-price auction payments. This is reflected in the prices starting from point $A$ and with no outstanding contracts: $b_{N}\left(s_{N}=A B\right)=2-\varepsilon$ and $b_{N-1}\left(s_{N-1}=A B\right)=$ $2-\varepsilon$ (price remains constant); $b_{N}\left(s_{N}=D A\right)=3-\varepsilon$ and $b_{N-1}\left(s_{N-1}=D A\right)=2-\varepsilon$ (price goes down). In addition, firstprice auction payment mechanisms may lead to inefficient ex ante allocations because the carrier prices the contracts above the marginal cost, i.e., the lowest expected cost carrier does not serve the contract even though it would be ex ante optimal to do so. The same phenomenon was observed by Figliozzi, Mahmassani, and Jaillet (2005) when simulating first and second-price sequential auction marketplaces.

\section{References}

Balas, E. 1989. The prize collecting traveling salesman problem. Networks 19 621-636.

Bent, R. W., P. Van Hentenryck. 2004. Scenario-based planning for partially dynamic vehicle routing with stochastic customers. Oper. Res. 52 977-987.

Bertsimas, D. J., P. Jaillet, A. R. Odoni. 1990. A priori optimization. Oper. Res. 38 1019-1033.

Branke, J., M. Middendorf, G. Noeth, M. Dessouky. 2005. Waiting' strategies for dynamic vehicle routing. Transportation Sci. 39 298-312.

Caplice, C. 1996. An optimization based bidding process: A new framework for shipper-carrier relationship. Ph.D. thesis, School of Engineering, MIT, Cambridge, MA.

Coyle, J., E. Bardi, R. Novac. 2000. Transportation, 5th ed. SouthWestern College Publishing.

Dai, Q. Z., R. J. Kauffman. 2002. Business models for Internet-based B2B electronic markets. Internat. J. Electronic Commerce 6 41-72.

Dantzig, G. B., J. H. Ramser. 1959. The truck dispatching problem. Management Sci. 6 80-91.

Dell'Amico, M., F. Maffioli, P. Värbrand. 1995. On prize-collecting tours and the asymmetric travelling salesman problem. Internat. Trans. Oper. Res. 2 297-309.

Feillet, D., P. Dejax, M. Gendreau. 2005. Traveling salesman problems with profits. Transportation Sci. 39 188-205.

Figliozzi, M. 2004. Performance and analysis of spot truck-load procurement markets using sequential auctions. Ph.D. thesis, School of Engineering, University of Maryland, College Park, MD.

Figliozzi, M., H. Mahmassani, P. Jaillet. 2003a. Framework for study of carrier strategies in auction-based transportation marketplace. Transportation Res. Record 1854 162-170.

Figliozzi, M., H. Mahmassani, P. Jaillet. 2003b. Modeling carrier behavior in sequential auction transportation markets. 10th Internat. Conf. Travel Behav. Res. (IATBR), Lucerne, Switzerland.

Figliozzi, M., H. Mahmassani, P. Jaillet. 2004. Competitive performance assessment of dynamic vehicle routing technologies using sequential auctions. Transportation Res. Record 1882 10-18.

Figliozzi, M., H. Mahmassani, P. Jaillet. 2005. Auction settings and performance of electronic marketplaces for truckload transportation services. Transportation Res. Record 1906 89-97. 
Figliozzi, M., H. Mahmassani, P. Jaillet. 2006. Quantifying opportunity costs in sequential transportation auctions for truckload acquisition. Transportation Res. Record 1964 247-252.

Gendreau, M., G. Laporte, R. Seguin. 1996. Stochastic vehicle routing. Eur. J. Oper. Res. 88 3-12.

Godfrey, G. A., W. B. Powell. 2002. An adaptive dynamic programming algorithm for dynamic fleet management, I: Single period travel times. Transportation Sci. 36 21-39.

Golden, B. L., L. Levy, R. Vohra. 1987. The orienteering problem. Naval Res. Logist. 34 307-318.

Hemert, J. van, J. A. La Poutre. 2004. Dynamic routing problems with fruitful regions: Models and evolutionary computation. Parallel Problem Solving from Nature VIII. Springer, New York.

Hvattum, L., A. Lokketangen, G. Laporte. 2006. Solving a dynamic and stochastic vehicle routing problem with a sample scenario hedging heuristic. Transportation Sci. 40(4) 421-438.

Ichoua, S., M. Gendreau, J. Y. Potvin. 2006. Exploiting knowledge about future demands for real-time vehicle dispatching. Transportation Sci. 40 211-225.

Jaillet, P. 1988. A priori solution of a traveling salesman problem in which a random subset of the customers are visited. Oper. Res. 36 929-936.

Jaillet, P., A. Odoni. 1988. Probabilistic vehicle routing problems in vehicle routing: Methods and studies. B. Golden, A. Assad, eds. Studies in Management Science and Systems, Vol. 16. North Holland, Amsterdam, The Netherlands, 293-318.

Kleywegt, A. J., J. D. Papastavrou. 1998. Acceptance and dispatching policies for a distribution problem. Transportation Sci. 32 127-141.

Krishna, V. 2002. Auction Theory. Academic Press, San Diego, CA.

Laporte, G., F. V. Louveaux. 1993. The integer L-shaped method for stochastic integer programs with complete recourse. Oper. Res. Lett. 13 133-142.

Laporte, G., F. Louveaux, H. Mercure. 1992. The vehicle-routing problem with stochastic travel-times. Transportation Sci. $\mathbf{2 6}$ 161-170.

Mitrovic-Minic, S., G. Laporte. 2004. Waiting strategies for the dynamic pickup and delivery problem with time windows. Transportation Res. Part B 38 635-655.

Mitrovic-Minic, S., R. Krishnamurti, G. Laporte. 2004. Doublehorizon based heuristics for the dynamic pickup and delivery problem with time windows. Transportation Res. Part B 38 669-685.

Nandiraju, S., A. Regan. 2005. Freight transportation electronic marketplaces: A survey of market clearing mechanisms and exploration of important research issues. Proc. 84th Annual Meeting Transportation Res. Board, Washington, D.C. (January).

Powell, W. B. 1986. A stochastic-model of the dynamic vehicle allocation problem. Transportation Sci. 20 117-129.

Powell, W. 1987. An operational planning model for the dynamic vehicle allocation problem with uncertain demands. Transportation Res. Part B 21B(3) 217-232.
Powell, W. B. 1996. A stochastic formulation of the dynamic assignment problem, with an application to truckload motor carriers. Transportation Sci. 30 195-219.

Powell, W., P. Jaillet, A. Odoni. 1995. Stochastic and dynamic networks and routing. M. O. Ball, T. L. Magnanti, C. L. Monma, G. L. Nemhauser, eds. Handbook in Operations Research and Management Science, Vol. 8, Network Routing. Elsevier, Amsterdam, The Netherlands, 141-296.

Powell, W., M. Towns, A. Marar. 2000. On the value of optimal myopic solution for dynamic routing and scheduling problems in the presence of user noncompliance. Transportation Sci. 34(1) $50-66$.

Sheffi, Y. 2004. Combinatorial auctions in the procurement of transportation services. Interfaces 34 245-252.

Solomon, M. M., J. Desrosiers. 1988. Time window constrained routing and scheduling problems. Transportation Sci. 22 1-13.

Song, J., A. Regan. 2005. Approximation algorithms for the bid construction problem in combinatorial auctions for the procurement of freight transportation contracts. Transportation Res. Part B 39914.

Stewart, W. R., B. L. Golden. 1983. Stochastic vehicle-routing-A comprehensive approach. Eur. J. Oper. Res. 14 371-385.

TCA. 2003. Truckload Carrier Association Website. http://www. truckload.org/infocenter/TCAdocs/info_08_02_02.htm.

Thomas, B. W., C. C. White. 2004. Anticipatory route selection. Transportation Sci. 38 473-487.

Tirole, J. 1989. The Theory of Industrial Organization. MIT Press, Cambridge, MA.

Topaloglu, H., W. Powell. 2002. Dynamic programming approximations for stochastic, time-staged integer multicommodity flow problems. Technical Report CL-00-02, Department of Operations Research and Financial Engineering, Princeton University, Princeton, NJ.

Topaloglu, H., W. B. Powell. 2003. An algorithm for approximating piecewise linear concave functions from sample gradients. Oper. Res. Lett. 31 66-76.

Toth, P., D. Vigo, eds. 2002. The Vehicle Routing Problem. Society for Industrial and Applied Mathematics, Philadelphia, PA.

Vickrey, W. 1961. Counterspeculation, auctions and competitive sealed tenders. J. Finance 16 8-37.

Wang, X. B., M. Xia. 2005. Combinatorial bid generation problem for transportation service procurement. Network Modeling 2005. Transportation Research Board Natl Research Council, Washington, D.C.

Yang, J., P. Jaillet, H. Mahmassani. 2004. Real-time multivehicle truckload pickup and delivery problems. Transportation Sci. 38 135-148.

$\mathrm{Zhu}, \mathrm{K}$. 2004. Information transparency of business-to-business electronic markets: A game-theoretic analysis. Management Sci. 50 670-685. 
Copyright 2007, by INFORMS, all rights reserved. Copyright of Transportation Science is the property of INFORMS: Institute for Operations Research and its content may not be copied or emailed to multiple sites or posted to a listserv without the copyright holder's express written permission. However, users may print, download, or email articles for individual use. 